\title{
NADPH Oxidase Deficiency: A Multisystem Approach
}

\author{
Giuliana Giardino, ${ }^{1}$ Maria Pia Cicalese, ${ }^{2,3}$ Ottavia Delmonte, ${ }^{4}$ Maddalena Migliavacca, ${ }^{2,3}$ \\ Boaz Palterer, ${ }^{5}$ Lorenzo Loffredo, ${ }^{6}$ Emilia Cirillo, ${ }^{1}$ Vera Gallo, ${ }^{1}$ Francesco Violi, ${ }^{6}$ \\ and Claudio Pignata ${ }^{1}$
}

\author{
${ }^{1}$ Department of Translational Medical Sciences, University of Naples Federico II, Naples, Italy \\ ${ }^{2}$ San Raffaele Telethon Institute for Gene Therapy (SR-TIGET), San Raffaele Scientific Institute, Milan, Italy \\ ${ }^{3}$ San Raffaele Telethon Institute for Gene Therapy (SR-TIGET), Pediatric Immunohematology and Bone Marrow \\ Transplantation Unit, San Raffaele Scientific Institute, Milan, Italy \\ ${ }^{4}$ Division of Immunology, Boston Children's Hospital, Boston, MA 02115, USA \\ ${ }^{5}$ Department of Experimental and Clinical Medicine, University of Florence, Florence, Italy \\ ${ }^{6}$ Department of Internal Medicine and Medical Specialties, Sapienza University of Rome, Rome, Italy \\ Correspondence should be addressed to Giuliana Giardino; giuliana.giardino@unina.it
}

Received 11 July 2017; Revised 11 October 2017; Accepted 2 November 2017; Published 21 December 2017

Academic Editor: Mark Crabtree

Copyright (c) 2017 Giuliana Giardino et al. This is an open access article distributed under the Creative Commons Attribution License, which permits unrestricted use, distribution, and reproduction in any medium, provided the original work is properly cited.

\begin{abstract}
The immune system is a complex system able to recognize a wide variety of host agents, through different biological processes. For example, controlled changes in the redox state are able to start different pathways in immune cells and are involved in the killing of microbes. The generation and release of ROS in the form of an "oxidative burst" represent the pivotal mechanism by which phagocytic cells are able to destroy pathogens. On the other hand, impaired oxidative balance is also implicated in the pathogenesis of inflammatory complications, which may affect the function of many body systems. NADPH oxidase (NOX) plays a pivotal role in the production of ROS, and the defect of its different subunits leads to the development of chronic granulomatous disease (CGD). The defect of the different NOX subunits in CGD affects different organs. In this context, this review will be focused on the description of the effect of NOX2 deficiency in different body systems. Moreover, we will also focus our attention on the novel insight in the pathogenesis of immunodeficiency and inflammation-related manifestations and on the protective role of NOX2 deficiency against the development of atherosclerosis.
\end{abstract}

\section{Introduction}

Nicotinamide adenine dinucleotide phosphate (NAPDH) oxidase (NOX) is a multimeric complex composed of enzymes of the NOX family [1]. NOX2 is a transmembrane protein firstly identified in phagocytic cells (e.g., neutrophils, eosinophils, and macrophages) [2] and dendritic cells [3-6]. It plays a crucial role in antimicrobial host defence and inflammation. NOX2 deficiency leads to the development of chronic granulomatous disease (CGD), a primary immunodeficiency characterized by life-threatening bacterial and fungal infections [7]. In addition to recurrent infections, patients with CGD also suffer from impaired inflammatory responses leading to the development of Crohn's-like inflammatory bowel disease (IBD) $[8,9]$ and other inflammatory complications $[7,10,11]$. Recently, increased reactive oxygen species- (ROS-) independent inflammasome activation and impaired autophagy, resulting in increased IL-1b release, have been shown in NOX2-deficient phagocytes [12, 13]. The treatment with the IL- $1 \mathrm{~b}$ receptor inhibitor (anakinra) resulted in decreasing the activation of inflammasome and in restoring autophagy in mice with CGD in vitro and in vivo. While the treatment seems to exert the same effect in human cells in vitro, the treatment in vivo is associated with contrasting results in humans [14, 15]. Rapamycin, a potent mammalian target of rapamycin (mTOR) inhibitor and autophagy inducer, has been shown to be able to restore autophagy and to regulate inflammasome activation in patients with CGD, unravelling new therapeutic opportunities for the treatment of inflammatory manifestations in 

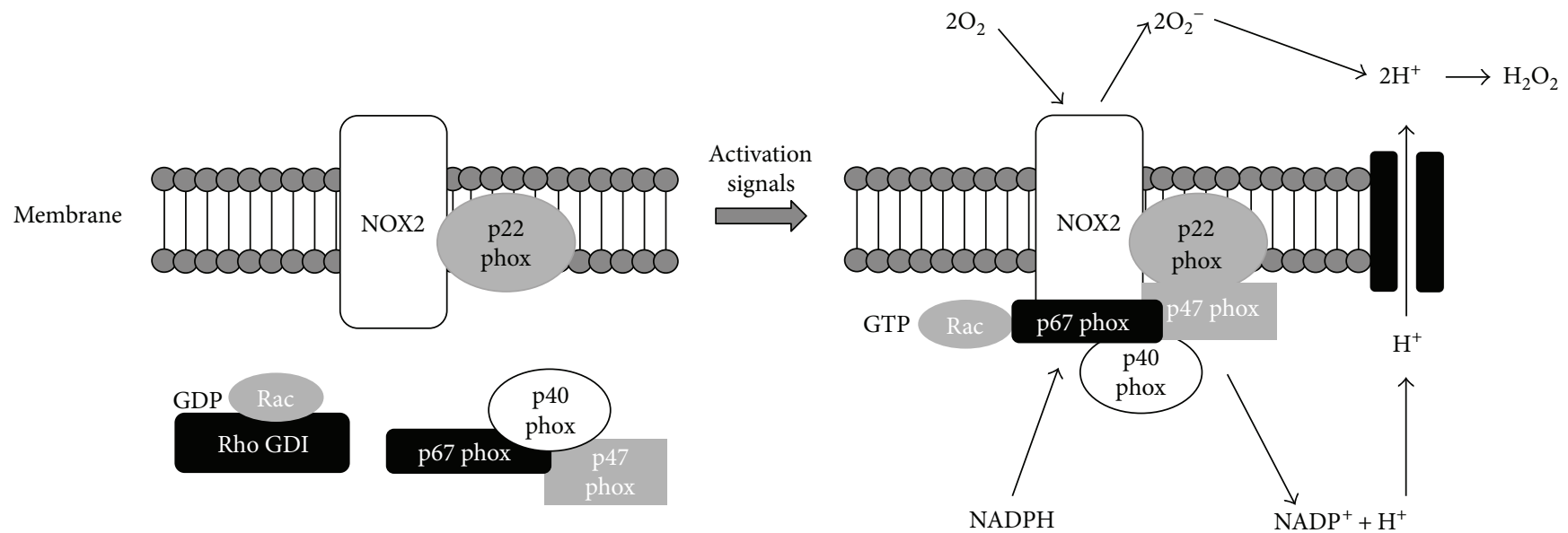

Cytosol

FIgURE 1: Schematic representation of the inactive and active forms of the NADPH oxidase complex. The complex consists of six subunits. NOX2 and p22phox are associated to form a heterodimer bound to the plasma membrane in both the inactive and the active forms. In resting conditions, p47phox, p67phox, p40phox, and the G-protein Rac are located in the cytosol. In the active form, the cytosolic subunits associate with the membrane-bound NOX2/p22phox heterodimer. The active NADPH oxidase generates superoxide $\left(\mathrm{O}_{2}^{-}\right)$by transferring electrons from NADPH inside the cell across the membrane and coupling them to molecular oxygen.

CGD $[16,17]$. Apart from its well-characterized role in the phagocyte function, NOX2 seems to be also implicated in the function of other different organs. In fact, NOX2 is also expressed in endothelial cells [18], cardiomyocytes [19], hematopoietic stem cells (HSC) [20, 21], and platelets [22] and its upregulation has been shown to be involved in neurodegenerative disease [23], neoplasms [24], and cardiovascular diseases [25-28]. Recent studies suggest that NOX2 activation is also involved in the development of atherosclerosis. In patients with CGD and in heterozygous carriers, the reduction of the ROS production is associated with increased levels of flow-mediated artery dilatation, thus implying a lower risk of developing atherosclerotic manifestations [29-32].

Other different NOX isoforms are implicated in diverse physiological functions, and they can be identified in numerous cell types [33]. Evidence suggest that NOX/DUOX enzymes are implicated in a number of biological processes including host defence, regulation of the vascular tone, hormone synthesis, fertilization, cell proliferation and differentiation, and formation of the extracellular matrix $[33,34]$.

In this review, we will summarize the effect of NOX2 deficiency in different body systems, focusing our attention on the novel insight in the pathogenesis of immunodeficiency and inflammation-related manifestations and on the protective role of NOX2 deficiency against the development of atherosclerosis. We will also focus on the novel insight in the definition of the clinical phenotype in heterozygous and female carriers and on the efficacy of novel and traditional potential therapeutic approach. Moreover, we will summarize the role of other NOX/DUOX enzymes in the function of different body systems and in the development of disease in humans.

\section{NADPH Oxidase: Structure and Function}

NOX plays a pivotal role in the production of ROS and, in particular, of the superoxide anion $\left(\mathrm{O}_{2}{ }^{-}\right)$at the expense of
NADPH. Seven genes have been identified encoding for NOX isoforms: NOX1 to NOX5, including CYBB gene encoding for NOX2, DUOX1, and DUOX2 [33, 35]. The different NOX isoforms in humans are involved in a wide range of cellular processes, including apoptosis, host defence, cellular signal transduction, oxygen sensing, and angiogenesis. Although NOX is ubiquitously expressed, the distribution of different isoforms is cell or tissue specific, allowing each NOX a distinct physiological and pathological function. All the members of the NOX family have conserved structural properties which are responsible for their catalytic activity. In particular, each homolog is composed of six or seven transmembrane domains, with two hemes in the $\mathrm{N}$-terminal region containing histidine residues and a NADPH-binding site in the cytoplasmic C-terminal. Moreover, all the isoforms form multimeric complexes characterized by the presence of a core catalytic subunit and up to five regulatory subunits [36]. The regulatory subunits have essential biological roles. In particular, the regulatory subunits p22phox, DUOX activator 1 (DUOXA1), and DUOXA2 are involved in the maturation and expression of the NOX/DUOX subunits in cell membranes; p67phox and NOX activator 1 (NOXA1) are essential for enzyme activation; p47phox, NOX organizer 1 (NOXO1) and p40phox have a role in spatial organization of the complex. Some NADPH oxidase isoforms, including NOX2, also rely on a small GTPase (RAC1 or RAC2) for their activation [37]. The NOX2 complex consists of six subunits, including two membrane molecules (NOX2 and p22phox), three with a cytosolic distribution (p47phox, p67phox, p40phox), and the G-protein Rac [1] (Figure 1) [33]. The catalytic core of the NOX2 complex is represented by a membrane heterodimer, composed of NOX2 and p22phox (Figure 1), which constitutes the flavocytochrome b558 [38]. It is constitutively expressed in the plasma membrane and in the membrane of specific granule of the neutrophils [39]. In this context, the NOX2 subunit plays a key role in the transfer of electrons 
from NADPH via FAD and heme to molecular oxygen within the phagosome [40] (Figure 1). NOX2 in humans is encoded by the $C Y B B$ gene and is composed of two domains, the N-terminal bis-heme cytochrome b, structured in a six a-helical transmembrane segment complexe, and the C-terminal FNR, which contains FAD- and NADPH-binding sites [41-43]. In resting cells, the NADPH oxidase cytosolic subunits, p47phox, p67phox, and p40phox associate in a trimeric complex through specific domains (Figure 1) [44-46]. In the active form of the NOX2 complex, the trimeric complex migrates to the plasma membrane where it interacts with NOX2 and p22phox. p47phox plays a prominent role in the processes of binding and translocation of the cytosolic subunits to the membrane and the subsequent anchoring to p22phox (Figure 1) [47]. In order to prevent ROS overproduction, the protein kinase $\mathrm{C}$ - (PKC-) related phosphorylation pathway is implicated in the modulation of these interactions and in particular in the regulation of the interaction between $\mathrm{p} 47$ phox and p22phox. In particular, in the free and complexed p47phox subunits, the interaction of the autoinhibitory region (amino acids 292-340) with the two SH3 domains prevents its binding to p22phox and, therefore, the NOX2 activation [48]. Upon stimulation, the phosphorylation of the specific serine residues, Ser 303 and 304, activates p47phox, thus allowing the recruitment of p67phox to the trimeric complex within the cytosol (Figure 1) [46, 49]. In turn, p47phox leads to membrane translocation through the binding to p22phox and contributes to the final assembly of the NOX complex that also includes the p22phox [50]. Rac2 and Rap1A, two proteins of the guanine nucleotide-binding proteins family, are also required for the full activation of the NOX complex [51]. Rac2 is located in the cytosol in a dimeric complex with Rho-GDI (guanine nucleotide dissociation inhibitor), while Rap1A is a membrane protein $[51,52]$. During the activation, the Rac2-guanosine triphosphate (GTP) complex translocates to the external membrane within the fully assembled multimeric cytosolic complex $[53,54]$. The role of Rap1A in the activation of NADPH oxidase is controversial (reviewed in [55]). In fact, Rapla is expressed at high levels in human neutrophils and copurifies with the p22 subunit of the NADPH oxidase [56-58]. Moreover, activating and inhibitory Rap1 mutants can modify the activity of the phagocyte NADPH oxidase [59, 60]. However, even though cell-free NADPH activation seems to be impaired when the cytosol of neutrophil is depleted of small GTPases and recombinant Rap1A is able to restore NADPH oxidase activation, normal levels of Rap1A have been identified in neutrophil membranes from patients with CGD, suggesting that the absence the cytochrome b558 does not affect the expression of this protein and its presence in the membrane [61]. On the other hand, even though the initial rate of $\mathrm{O}_{2}{ }^{-}$ in response to formylated peptide and phorbol ester was reduced in Rap1a-/- mice, the sustained induction of superoxide production was not significantly reduced, suggesting that unlike Rac2, Rap1A is not necessary for the response of the neutrophil to formylated peptide or phorbol ester [62].
The interaction with the regulatory proteins present in the cytosol is able to induce a conformational change in NOX2 which leads to its activation and to the electron flow. Studies in vitro suggest that the activation of the oxidase may be obtained in the absence of p47phox but not in the absence of p67phox or Rac [63-65]. Moreover, evidence suggests that $\mathrm{p} 67$ phox plays a pivotal role in the conformational remodelling of NOX2 [66-68]. In particular, the region comprising the residues 199-210 [69] or 190-208 [70] of p67phox has been identified as responsible of the activation of the oxidase.

NOX2 complex plays a key role in killing the microorganisms in phagocytic leukocytes. In particular, the interaction of the external membrane of the phagocytic cell with the bacteria leads to the internalization of a segment of the plasma membrane. This interaction eventually leads to the formation of the intracellular vesicle, where the oxidants $\mathrm{O}_{2}{ }^{-}$and $\mathrm{O}_{2}$-derived products promote $\mathrm{K}^{+}$influx and induce an increase of the $\mathrm{pH}$ within the phagosome [71]. The increase in $\mathrm{pH}$ and the $\mathrm{K}^{+}$influx provides an optimal milieu for the activation of the functions of the major granule proteases, elastase, cathepsin G, and proteinase 3 [72]. In fact, the alkaline $\mathrm{pH}$ together with the $\mathrm{K}^{+}$influx is able to promote the dissociation of these enzymes from the anionic sulphated proteoglycan matrix to which they are bound.

NOX1 was the first homolog of NOX2 to be described [73]. The NOX1 gene maps on the X-chromosome both in humans and mice. NOX1 is highly expressed in the colon epithelium [74]; however, it is also expressed in other cell types, including vascular smooth muscle cells, endothelial cells, and osteoclasts. NOX1 functions in a complex with p22phox [74] and requires two additional proteins, NOXO1 and NOXA1, which are also present in the colon epithelium. NOX1 is activated by the small GTPase Rac, which acts through a direct binding to NOX1 or to the TPR domain of the activator subunit NOXA1. Recent studies in mouse models suggest that NOX1 is implicated in the control of cell proliferation induced by different bacteria, including Lactobacilli [75]. NOX1 may also contribute to mucosal repair after injury, as suggested by the evidence of impaired mucosal healing in an intestinal epithelial-specific Nox1 knockout model [76].

The gene encoding for human NOX3 maps on chromosome 6. NOX3 is specifically expressed in the inner ear, where it is required for the proper development of otoconia crystals of the vestibular system. It can also be expressed at low levels in the fetal spleen, fetal kidney, skull bone, and brain [77-80]. NOX3 depends on p22phox for its activation [81, 82]. Indeed, the production of ROS by NOX3 is inhibited by truncated p22phox [81]. However, no vestibular dysfunction has been reported for $\mathrm{p} 22$ phox-deficient CGD patients.

NOX4 was first identified in kidney epithelial cells, but subsequently, its expression has been detected also in several other cell types, including vascular smooth muscle (VSMC), endothelial cells, cardiomyocytes, skeletal muscle, osteoclasts, neurons, and microglia [33, 83]. Differently from other NOX complexes, the activity of NOX4 does not require cytosolic regulatory subunits even though its activity seems to be enhanced by association with p22phox [70]. Furthermore, 
NOX4 is the only member of the family which localizes to mitochondria, contributing to mitochondrial ROS levels $[84,85]$.

NOX5 is expressed in the spleen testis and endothelial cells [86]. NOX5 oxidase is likely to function as a standalone protein since no interactions with any of the known regulatory subunits have been detected. NOX5 oxidase has a unique amino terminal $\mathrm{Ca} 2^{+}$-binding domain which allows NOX5 oxidase activity to be regulated by increases in cytosolic $\mathrm{Ca}^{+}$concentration, which could be important in chronic vascular diseases [87].

DUOX1 and DUOX2 were initially cloned from porcine and human thyroid glands [88, 89]. However, their expression does not seem to be confined to the thyroid gland. In fact, they are also expressed in the respiratory and gastrointestinal tracts [90-93] where they are involved in the host defence. DUOX1 and DUOX2 differ from the other NOX isoforms because of the homology of the N-terminal domain with the peroxidases [94]. Moreover, NOX5 [95], DUOX1, and DUOX2 [96] are calcium-dependent NADPH oxidase. Finally, while similarly to NOX2, NOX1, NOX3, and NOX5 produce $\mathrm{O}_{2}{ }^{-}$, which is subsequently converted into $\mathrm{H}_{2} \mathrm{O}_{2}$, NOX4, DUOX1, and DUOX2 are able to directly produce $\mathrm{H}_{2} \mathrm{O}_{2}$. The activity of DUOX is itself regulated by $\mathrm{H}_{2} \mathrm{O}_{2}$ levels $[97,98]$. The $\mathrm{H}_{2} \mathrm{O}_{2}$ produced by DUOX2 is able to support the generation of hypothiocyanite, an antimicrobial compound effective against a broad range of bacteria [99-101]. In the thyroid gland, the $\mathrm{H}_{2} \mathrm{O}_{2}$ generated by DUOX2 is necessary to allow the oxidation of the iodide by thyroid peroxidase (TPO) [102]. DUOX2 mutations lead to thyroid dyshormonogenesis, resulting in transient to severe congenital hypothyroidism.

\section{NADPH Oxidase Deficiency: Model of Inheritance}

Mutations in one of the genes encoding the components of the NADPH oxidase complex cause chronic granulomatous disease (CGD), a rare inherited immunodeficiency syndrome with an estimated frequency of $1 / 200,000$ to $1 / 250,000$ newborns. The disorder can be inherited in an X-linked or autosomal recessive (AR) manner and comprises four main genetic forms. The most common form of CGD is the Xlinked recessive CGD caused by mutations in the $C Y B B$ gene, encoding the NOX2 protein. X-CGD represents about $60-$ $70 \%$ of the total cases reported to date [103]. The other forms of CGD are AR and are due to mutations in CYBA, NCF1, and NCF2, encoding p22phox, p47phox, and p67phox, respectively [104]. p47phox deficiency is responsible for approximately $30 \%$ of AR-CGD, while p22phox and p67phox deficiencies account for the remaining 10\% of cases (about $5 \%$ each). To date, only one case of AR-CGD due to mutation of the NCF4 gene, encoding p40phox, has been reported [105]. Different kinds of mutations have been so far reported, including small indel, missense, nonsense, and splice mutations. Missense mutations are frequent in XRCGD, reducing the NOX2 expression and functionality in phagocytes at a different extent. The X910 variant identifies the form with null protein and oxidase activity; X91- refers to the form with residual protein expression and reduced, but not absent activity, whereas the X91+ variant is characterized by the normal expression of the protein, which, however, is not functional. Again, in the AR forms, the proteins may be absent (A470, A220, and A670) or normally expressed with residual activity of NADPH oxidase.

Dominant negative RAC2 mutation has been reported in 2 male infants [106-108]. In the first case, it was associated with soft tissue infections, neutrophilia, and neutrophil chemiotaxis deficiency $[106,107]$. The second case was identified in the context of the newborn screening for severe combined immunodeficiency because of a reduction of the $\mathrm{T}$ cell receptor excision circles [108]. Apart from the neutrophil dysfunction, this patient also showed leukocytosis, CD4 lymphopenia, and reduced levels of IgA and IgM [108]. More recently, whole exome sequencing revealed a homozygous nonsense loss of function mutation in two siblings with common variable disease, born to consanguineous parents [109]. The clinical phenotype was characterized by recurrent sinopulmonary infections, bronchiectasis, failure to thrive, poststreptococcal glomerulonephritis, coagulation factor XI deficiency, urticaria, food allergy, erythematous plaques, arthralgia, autoimmune thyroiditis, growth hormone deficiency, and hyperparathyroidism. The immunological phenotype included progressive hypogammaglobulinemia, requiring replacement therapy; reduced CD19+ B cells; inverted $\mathrm{CD} 4+/ \mathrm{CD} 8+$ ratio; reduced $\mathrm{CD} 4+, \mathrm{CD} 8+$, and recent thymic emigrants; and reduced regulatory $\mathrm{T}$ cells. The studies on the neutrophils revealed impaired chemiotaxis, reduced number of neutrophil granules, and morphological changes of the secondary granules. However, neutrophil dysfunction in these patients was not associated with the development of severe clinical manifestations in the neonatal period. The impairment of the $\mathrm{B}$ and $\mathrm{T}$ cell compartments observed in these patients supports the role of RAC2 in the B and T cell development, also observed in mouse models [110-113].

\section{Chronic Granulomatous Disease: Clinical Manifestations}

CGD is characterized by an increased susceptibility to recurrent or severe infections due to fungal or bacterial pathogens. Infections are typically caused by catalase-positive bacteria and fungi. The most common microorganisms are Aspergillus species, Staphylococcus aureus (S. aureus), Burkholderia (Pseudomonas) cepacia complex (B. cepacia), Serratia marcescens (S. marcescens), and Nocardia species [14]. Salmonella and Bacillus Calmette-Guérin (BCG) are common pathogens in patients coming from countries with high prevalence of Salmonella, with endemic tuberculosis and mandatory $B C G$ vaccine (Table 1 ). Other rare bacterial species have been recognized in patients with CGD, and the identification of these pathogens is virtually pathognomonic of the disease (Table 1). Among those, it is important to mention sepsis by brackish water organisms Chromobacterium violaceum [114] and Francisella philomiragia [115]. Another emerging cause of necrotizing lymphadenitis and sepsis are methylotrophs like [116] Granulibacter bethesdensis [117, 118], Acidomonas methanolica [119], and Methylobacterium lusitanum [120]. 
TABLE 1: Microorganisms causing infections in CGD

\begin{tabular}{lc}
\hline Common & Reference \\
Aspergillus species & \\
Staphylococcus aureus & \\
Burkholderia cepacia complex & \\
Serratia marcescens & {$[14]$} \\
Nocardia & \\
Salmonella & \\
Bacillus Calmette-Guérin (BCG) & \\
Pathognomonic & \\
Chromobacterium violaceum & {$[114]$} \\
Francisella philomiragia & {$[115]$} \\
Granulibacter bethesdensis, & {$[117,118]$} \\
Acidomonas methanolica & {$[119]$} \\
Methylobacterium lusitanum & {$[120]$} \\
Actinomycosis & {$[121]$} \\
A. nidulans and viridinutans & {$[136]$} \\
Neosartorya udagawae & {$[137]$} \\
Paecilomyces lilacinus and variotii & {$[139,140]$} \\
Geosmithia argillacea & {$[141-143]$} \\
Penicillium piceum & {$[144]$} \\
Phellinus species & {$[145]$} \\
\hline
\end{tabular}

PCR for $16 \mathrm{~S}$ rRNA is necessary for the identification of the atypical pathogens [116]. Chronic recurrent pulmonary, hepatic, and cervicofacial infections by catalase-negative actinomycosis have also been reported [121]. Table 1 summarizes the most common and the pathogenetic microorganisms isolated in patients with CGD.

Median age at diagnosis ranges from 2.5 to 3 years. Two thirds of the patients are diagnosed in the first year of life and usually before 5 years of age. The X-linked variants display a more severe clinical picture, accounting for most of the early presentations. On the other hand, AR variants can display milder phenotypes and delayed diagnosis [122-128]. The most common sites of infections are the lungs, lymph nodes, skin, and liver, even though also the bones, kidneys, gastrointestinal tract, and brain may be affected. Presenting features may also include diarrhea, failure to thrive, delayed wound healing, and granuloma formation in multiple organs. Clinical manifestations may be very different among patients.

4.1. Lung Involvement in CGD. Pulmonary infections are the most common manifestations among all the disease variants. Radiologic findings include consolidation, nodules, areas of scarring, traction bronchiectasis, emphysema, air trapping, mediastinal and hilar lymphadenopathy, pulmonary artery enlargement, and pleural effusion [129]. Pneumonias are recurrent and resistant to standard therapy and can often complicate with granulomatous hilar lymphadenopathy, mimicking sarcoidosis, lung abscesses, and empyema. S. aureus was the most common pathogen in lung infections previous to the use of trimethoprim/sulfamethoxazole prophylaxis. In the postprophylaxis era, other bacteria and fungi are the more common causes of pneumonia. B. cepacia complex may lead to severe lung infections, bearing a significant morbidity due to the resistance to first-line empiric antibiotic treatments and the delayed diagnosis related to the difficulties in its isolation and growth [130]. Lung infections by Nocardia often require invasive techniques for the isolation and the definition of specific antibiotic therapies. In one third of the cases, Aspergillus infections are identified along with Nocardia infections, probably because both of them are acquired through inhalation [131]. Interestingly, differently from fungal infections, Nocardia is able to cause lung cavitations in patients with CGD. In countries with endemic tuberculosis or mandatory $B C G$ vaccine, localized or widespread mycobacteria infections are very common, leading to the diagnosis in most of the cases. In a recent survey, mycobacterial infections were identified as responsible for $6 \%$ of pneumonias in American patients with CGD [124]. Infections by environmental mycobacteria like $M$. leprae or M. ulcerans are uncommon. BCG vaccine is contraindicated in patients with CGD $[132,133]$. Fungal infections due to inhalation of spores and hyphae are an important cause of morbidity in patients with CGD, and they lead to diagnosis in most of the cases. They may present with insidious and subclinical courses, with aspecific symptoms like growth failure and asthenia, low-grade fever, cough or chest pain, and mild leukocytosis. On the other hand, the inhalation of aerosolized decayed organic matter, including fungi, can cause an acute fulminant pneumonitis also known as "mulch pneumonitis" [134]. Lung infections are typically caused by Aspergillus species (Figure 2(a)), and A. fumigatus is the most common [135]. Other variants like A. nidulans [136], A. viridinutans, and Neosartorya udagawae [137] are almost pathognomonic for CGD and can cause invasive spreading disease to the bones and nervous system [138]. Other fungal pathogens isolated in patients with CGD include molds Paecilomyces lilacinus [139] and variotii [140], Geosmithia argillacea [141-143], the fungus Penicillium piceum [144], and the basidiomycetes of the Phellinus species [145]. The recognition of atypical fungal infections can be challenging due to the need for nonstandard culture conditions. For this reason, extensive and aggressive diagnostic approaches, including molecular diagnostic, should be always undertaken in order to identify the pathogens, especially when the patient is under mold prophylaxis $[138,146]$. Yeast infections are less common in patients with CGD. Mucormycosis has been only reported in the setting of immunosuppression [137], and dimorphic mold infections like Coccidioidomycosis and Blastomycosis are not typical [147].

4.2. The Skin and Lymph Nodes. Cutaneous involvement with abscesses and deep seeded infections is also common. The pathogens implicated are typically $S$. aureus, catalasepositive and gram-negative bacteria. Cutaneous abscesses may often require prolonged antibiotic courses, incision, and drainage procedures for resolution. Impetigo in the nasal area and resistant facial acne caused by $S$. aureus also require long courses of local and systemic antibiotics [148-154]. Suppurative adenitis due to $S$. aureus has been reported. Granulibacter bethesdensis is an environmental organism that can 


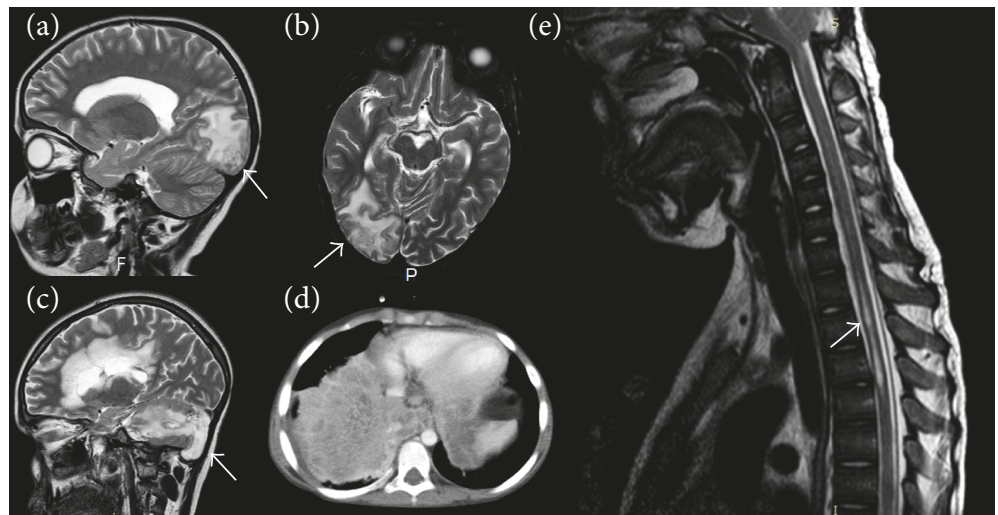

FIGURE 2: Invasive fungal infections in patients with CGD. $(\mathrm{a}, \mathrm{b})$ Cerebral invasion (arrows) in a patient with invasive pulmonary aspergillosis. (c) Cerebellar aspergillosis (arrow). (d) Invasive pulmonary aspergillosis. (e) Spinal cord invasion (arrow) in a patient with pulmonary aspergillosis.

lead to necrotizing pyogranulomatous lymphadenitis and in rare cases fatal bacteremia. Noninfectious manifestations of CGD include photosensitivity, discoid lupus, granulomatous lesions, and vasculitis. Patients with CGD display typically delayed and abnormal wound healing caused by excessive granulation, causing scarring and wound dehiscence [151].

4.3. The Liver. Hepatic and perihepatic abscesses are common in CGD. Liver involvement may lead to morbidity due to the challenging diagnosis and treatment. Presentation can be subtle, with aspecific systemic symptoms. Differently from hepatic abscesses in immunocompetent patients, commonly caused by enteric bacteria, abscesses in CGD are mainly caused by staphylococci. These abscesses are usually very dense and may require difficult surgical procedures in most of the cases. Recently, the association of high-dose steroids and antibiotic regimens has been proved to be an effective surgical sparing approach $[155,156]$. Noninfectious causes of liver involvement in patients with CGD include toxic drug-induced hepatitis, hepatosplenomegaly due to portal venopathy, and nodular regenerative hyperplasia. The development of noncirrhotic portal hypertension is a negative prognostic factor $[157,158]$.

4.4. Metastatic Infections. Osteomyelitis is one of the most important metastatic infections in patients with CGD. It is characteristically multifocal, with other organs involved, caused by typical CGD pathogens like S. marcescens or Aspergillus species. Biopsy reveals signs of chronic inflammation and granulomatous features $[159,160]$. Infection spreading can also affect the central nervous system, presenting with meningitis, brain, and epidural abscesses (Figures 2(b)-2(e)) [148-150]. Genitourinary tract involvement is also frequent (38\%), but often occult. Granulomatous cystitis, ureteral and urethral obstruction, prostate abscesses, bladder granulomata, and urinary tract infections have been reported [161-164]. Chorioretinal lesions are relatively common in patients with CGD, typically with "punched out" lesions associated with pigment clumping lying in line with the retinal arteries. Those lesions appear to be nonprogressive and usually do not impair vision [165]. Since bacterial DNA was isolated from those lesions, infections may play a role in the pathogenesis [166]. However, these lesions in most cases do not progress during immunosuppression suggesting that they are not sites of active infections [122]. Patients can also present with blepharokeratoconjunctivitis and pannus formation [167].

4.5. The Gastrointestinal Tract. The gastrointestinal tract is extensively affected in patients with CGD. Granulomatous disease-mimicking Crohn's disease, affecting the oesophagus, stomach, jejunum, ileum, cecum, and rectum, is common [8, 152-154, 168]. Also, the upper gastrointestinal tract may be involved in the forms of gingivitis and gingival hypertrophy, stomatitis, and aphthosis. Around a third of patients are affected, being more frequent in the X-linked forms (43\%) then in the autosomal recessive $(11 \%)$. In some cases, it may represent the only manifestation of the disease. In such cases, diagnosis may be challenging [169]. Clinical presentation is variable, ranging from gastric outlet obstruction [170], malabsorption, vitamin B12 deficiency to classic inflammatory bowel disease symptoms like abdominal pain, diarrhea, fistulae, and strictures. CGD-related colitis is often resistant to the standard inflammatory bowel disease therapies. The treatment with anti-TNF- $\alpha$ drugs has been successfully used to treat fistulas, but it may increase the risk of severe infections [171].

4.6. Brain Disease. The assessment of cognitive function in 23 patients with CGD revealed an increased prevalence of cognitive deficit (IQ<70\%) [172]. However, this evidence was not confirmed in a subsequent study [173]. It should be noted that in both the studies, the sample size was quite small to draw definitive conclusions. Considering the role of superoxide generation in brain hippocampal synaptic plasticity and hippocampus-dependent memory, this subject deserves further studies [174]. On the other hand, increased levels of NOX2 have been detected in microglia and infiltrating macrophages in brain autopsies from patients with initial multiple sclerosis, suggesting a role of ROS in the pathogenesis of demyelination and neurodegeneration [175]. This 
hypothesis has been confirmed by the evidence of the involvement of NOX2 in motor neuron degeneration in a mouse model of amyotrophic lateral sclerosis [176].

4.7. Growth Defect. Children with CGD usually attain a height within their target by adulthood, despite being generally small for their age in early childhood. Growth failure might be linked to colitis and malabsorption and to the chronic and frequent infections [177]. Regardless of the cause, hematopoietic cell transplantation is able to reverse most of the cases of growth defect [178].

4.8. Laboratory Findings. Patients with CGD may show a mild to moderate leukocytosis, elevation of acute phase reactants, and polyclonal hypergammaglobulinemia. A chronic microcytic anemia due to chronic disease and iron deficiency may be observed at the onset of the disease, especially in association with colitis. Patients can also display a T CD4+ lymphopenia $[179,180]$.

4.9. McLeod Phenotype. The CYBB gene, responsible of the Xlinked CGD variant, is located at the Xp21.1 locus. Deletions across this locus can also involve adjacent genes, generating complex phenotypes. Telomerically to the X-CGD locus, there are the Kell erythrocyte antigens. Their deletion causes the McLeod phenotype, a syndrome with haemolytic anemia associated with neuroacanthocytosis $[181,182]$. For this reason, patients with X-linked CGD need to be carefully evaluated for their Kell phenotype in order to avoid sensitization and transfusion reactions [183]. Larger telomeric deletions can also involve the retinitis pigmentosa GTPase regulator $(R P G R)$ gene, responsible for X-linked retinitis pigmentosa, and $D M D$, causing Duchenne muscular dystrophy. Large centromeric deletions can involve the OTC gene, causing ornithine transcarbamylase deficiency [184].

\section{Williams Syndrome}

Williams syndrome (WS) is a rare genetic disorder, affecting $1 / 20000$ newborns, characterized by neurodevelopmental alterations leading to mild-to-moderate mental retardation and characteristic craniofacial features. Supravalvular aortic stenosis and hypercalcemia in infancy may also feature the disease. WS is due to a heterozygous segmental microdeletion (about 1.5-1.8 Mb) at chromosomal band 7q11.23 . This deletion involves about 20 genes and, in some cases, it may also include the NCF1 gene. In extremely rare cases, the WS microdeletion may be associated with a mutation in NCF1 on the other allele. When the WS deletion includes $N C F 1$, this combination leads to the development of CGD $[185,186]$.

\section{NADPH Oxidase Deficiency and Autoimmunity: A Focus on Female Carriers and Patients Carrying Oxidase Gene Polymorphisms}

Autoinflammatory and autoimmune disorders have been identified in patients with CGD, female carriers for NOX2 deficiency, and patients carrying oxidase gene polymorphisms, suggesting a role for NADPH oxidase in the pathogenesis of autoimmunity and in the in regulation of the adaptive immune responses [187-189]. In a recent study, Wen et al. showed that NOX2 is critical for the correct functioning of the suppressive machinery of CD8+ T regulatory cells (CD8 Treg) [190]. In particular, CD8 Treg are able to control the intensity of effector $\mathrm{T}$ cell responses by releasing NOX2containing microvesicles which are in turn taken up by the target cells [190]. NOX2-derived ROS abrogate the phosphorylation of ZAP70 and LAT preventing the activation of the effector cell [190]. This mechanism is impaired in older individuals and is related to the development of autoimmunity [190]. Finally, NOX2 overexpression is able to restore the suppressive function of CD8 Tregs from older donors [190].

Genome-wide association studies (GWAS) have revealed the association between genes-encoding oxidase subunits and autoinflammatory and autoimmune disorders. The most common autoimmune manifestations in CGD are systemic lupus erythematosus (SLE) [124-126, 191, 192], followed by thrombocytopenic purpura (ITP) [124-126, 191, 193-195] and arthritis [125, 192, 193, 196]. Variations in NCF2, encoding p67phox, and NCF4, encoding p40phox, have been associated with SLE [197] and with rheumatoid arthritis [198] and Crohn's disease [199, 200], respectively. Moreover, a recent study revealed that $\mathrm{p} 47$ phox-deficient patients are at greater risk of developing severe diabetes and the related complications, including renal and cardiovascular disease, as compared with patients with NOX2 deficiency [201]. Similarly, GWAS studies revealed variants in NOX2 complex components in patients suffering from very early onset inflammatory bowel disease (VEOIBD) [202-204]. Apart from NOX2, also other NOX homologues seem to play a role in the development of VEOIBD. In a recent study, two variants of NOX1 have been identified in three patients with severe pancolitis [205]. The first patient carried a missense variant located upstream of the first FAD-binding domain. This mutation lead to a reduction of ROS generation by $50-60 \%$ [205]. The second variant was located in the second FAD-binding domain and led to a $60-80 \%$ decrease in ROS production. Similarly, a DUOX2 missense variant was identified in a patient with recurrent pancolitis, complicated by perforation and colectomy. The variant was located in the third intracellular loop and leads to reduced $\mathrm{H}_{2} \mathrm{O}_{2}$ generation [205]. A second DUOX variant located in the highly conserved GRP sequence in the third $\mathrm{NADPH}$-binding domain was identified in a patient with pancolitis [205]. This variant also led to decrease in $\mathrm{H}_{2} \mathrm{O}_{2}$ release [205].

Female carriers for NOX2 deficiency are not completely asymptomatic. In affected women, lyonization determines two populations of phagocytes. One with normal oxidative activity and another with impaired oxidative activity. Usually, 15 to 20 percent of wild-type cells are sufficient to handle infections. However, in case of unbalanced lyonization leading to less than 20 percent of normal oxidase activity, female subjects can show mild to severe CGD phenotype (Figure 3). Skewing of X-chromosome inactivation can be progressive 


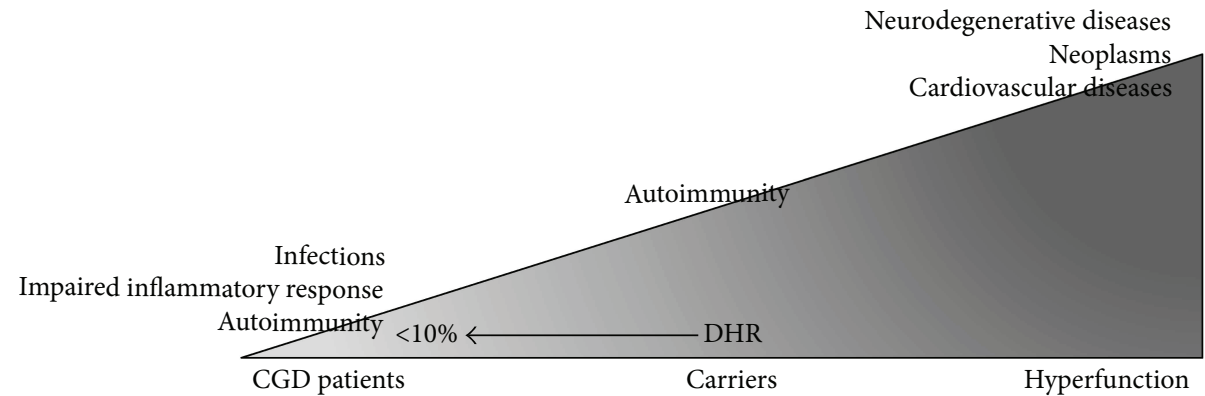

FIGURE 3: Spectrum of clinical manifestations associated with marked reduction (dihydrorhodamine (DHR) $<10 \%)$, slight reduction, and increase of the NOX2 activity. The complete absence of NOX2 activity leads to the development of infectious, inflammatory and autoimmune complications observed in CGD. A partial reduction of the NOX2 activity, observed in female carriers, may lead to the development of autoimmune complications. Upregulation of NOX2 has been observed in different cardiovascular and neurodegenerative disorders and in neoplasms.

with aging leading to late onset CGD manifestations and increased rate of autoimmunity including inflammatory bowel disease [206-209]. The most common findings in heterozygous female carriers are photosensitive skin rashes (58\%), mouth ulcers (42\%), and joint pain (37\%). The cutaneous rash closely resembles chronic discoid lupus, even though systemic lupus serologic markers are usually negative (Figure 3) [210-212]. Asymptomatic carriers can also have the typical chorioretinal lesions. All the abovementioned manifestations seem to be associated with skewed lyonization $[165,167]$. In a few cases, a severe phenotype, requiring HSCT, has been described in X-CGD female with nonrandom X-chromosome inactivation [213].

Both the X-CGD carrier status and X-chromosome inactivation can be identified with the dihydrorhodamine (DHR) 123 testing. Recently, Marciano et al. studied a large cohort of $\mathrm{X}$-linked CGD female comparing the presence of infections and/or autoinflammatory manifestations with the levels of DHR in the peripheral blood neutrophil. Overall, $48 \%$ of XCGD carrier had a clinical history of infections and/or autoimmune or inflammatory manifestations. A significant correlation was found between the development of infections and levels of DHR lower than 20\%. Furthermore, the authors found that carriers more prone to develop severe infections had DHR lower than $10 \%$. No correlation was found between different NOX2 mutations and \% of DHR values. However, differently from what was observed for the infections, it was not possible to find any relationship between the DHR levels and the incidence of autoimmune or inflammatory manifestations. These data support the hypothesis that, differently from infectious complications, the development of inflammatory manifestations is not correlated with the residual reactive oxygen intermediate production but to the carrier status per se. Further factors, including the influence of confounder genes, and environmental factors such as the microbiome may contribute to the development of these manifestations [191, 214]. Considering that the $\mathrm{X}$ inactivation can be different between tissues, further studies are necessary to define the role of $\mathrm{X}$ inactivation in the pathogenesis of inflammatory or autoimmune manifestations in X-CGD carriers.

\section{NADPH-Dependent ROS Deficiency and Autophagic Dysfunction: Implication for Infectious Response and Inflammasome Activation}

Autophagy is implicated in many tissue-specific functions and cellular pathways, including those involved in both innate and adaptive immunity $[215,216]$. Autophagy is a fundamental metabolic pathway implicated in delivering cytoplasmic proteins and organelles to the lysosome for degradation. Recent evidence suggests that autophagy is also implicated in innate immune response pathways and in particular in targeting intracellular bacteria in the cytosol and in limiting bacterial growth in damaged vacuoles and phagosomes. The process, also known as "xenophagy," involves the formation of double-membrane compartments, namely, autophagosomes, around target bacteria and their transport to lysosomes, where they are degraded $[217,218]$. In particular, this mechanism seems to be mainly implicated in the defence against intracellular infectious agents, including Mycobacterium tuberculosis, Salmonella, Shigella, Legionella, Burkholderia species, and Aspergillus fumigatus [219-221]. Most of these infectious agents are usually responsible for fatal or severe infections in patients affected with CGD. On the other hand, bacteria have developed several mechanisms to impair autophagy interfering with autophagy signalling or the autophagy machinery [222]. The evidence that the LC3 (light chain 3) protein, a member of the autophagy-related family (Atg) and beclin 1, another autophagic component, is able, upon bacterial cellular engulfment, to bind to the phagosomes promoting their fusion with lysosomes and the killing of the enclosed microbes suggested that autophagy may be implicated in antimicrobial defence [223]. This process has been found strongly decreased in phagocytes from Nox2 KO mice [224]. Furthermore, it has been observed that in both human and murine models of CGD macrophages, which explain a permissive phenotype for bacterial replication, autophagy induction by rapamycin, a mammalian target of rapamycin (mTOR) inhibitor, is able to reduce $B$. cenocepacia bacterial burden, suggesting that the increase of 
the autophagic flux may represent a potential therapeutic approach to improve bacterial clearance in CGD [219]. A normal ROS production is considered indispensable for the physiological activation of the autophagic process [225]. On the other hand, the integrity of the autophagic machinery results in the inhibition of IL- $1 \beta$ production. In a recent study, ROS deficiency has been associated with defects of autophagic mechanism in both mice and patients with CGD. In this study, the human subunit p47phox was showed to be fundamental for LC3 recruitment after the bacterial internalization. Moreover, it was observed that IL- $1 \beta$ production from human CGD monocytes was significantly increased as compared to normal controls. The blocking of the IL-1 receptor with anakinra resulted in a significant reduction of the inflammation in $p 47$ phox $-1-$ mice affected with colitis associated with a reduced production of inflammatory cytokine. A clinical improvement of the colitis and perirectal abscesses was, also, observed in two CGD patients affected with active colitis, treated with the same drug [15]. Unfortunately, anakinra did not induce a clinical remission in further five cases [14]. According to the indication of the European Medicines Agency, the dose of anakinra may be gradually increased to a maximum of $8 \mathrm{mg} / \mathrm{kg} /$ day, based on the individual therapeutic response (http://www.ema. europa.eu/docs/en_GB/document_library/EPAR_-_Product_ Information/human/000363/WC500042310.pdf). Since in the study by Hahn et al. the protocol of treatment and exact dose of drug used per patient are not specified, it is not possible to rule out that the dose of drug used was too low. The treatment with anakinra was shown to be able to modulate the increased inflammasome activation and to restore the abnormal autophagy in both human and mouse cells. In CGD mice infected with Aspergillus fumigatus, the treatment with anakinra was also associated with a reduction of fungal growth and granuloma formation resulting in an increased survival. This last evidence suggests that the pharmacological restoration of the autophagy may be also useful in treating severe fungal infection. In a further study by Gabrion et al. [17], rapamycin was able to induce a reversion of CGD inflammatory status in different immune cells of patients with CGD. In particular, rapamycin was able to induce a reduction of the production of IL-1 $\beta$, IL-6, IL-23, and TNF-alpha in macrophage stimulated with LPS, a reduction of the IL-6/IL-10 proinflammatory ratio, and a decrease of the inflammasome activation. Moreover, the addition of low doses of anakinra was able to potentiate the inhibitory effect of rapamycin on IL- $1 \beta$ secretion in vitro. Therefore, drugs that modulate autophagy may represent a potential therapy for both infectious and inflammatory manifestations associated to this complex congenital disorder.

\section{NADPH Oxidase Upregulation and Vascular Disease}

Apart from the phagocytes, where it has been originally identified, NOX2 is also expressed in endothelial cells [18], cardiomyocytes [19], hematopoietic stem cells [20, 21], and platelets [22]. NOX2 upregulation has been shown to be involved in neurodegenerative diseases [23], neoplasms [24], and cardiovascular diseases [25-28]. NOX can exert damaging as well as protective roles in the vascular system. In fact, while a regulated production of $\mathrm{H}_{2} \mathrm{O}_{2}$ is necessary to maintain the integrity of the endothelial system and to control the inflammatory response [226], on the other hand, the hyperproduction of $\mathrm{H}_{2} \mathrm{O}_{2}$ may lead to inflammation, oxidative stress, and endothelial disfunction [227-229]. Among the different vascular NADPH oxidase isoforms, NOX2 is the most widely expressed and it has been identified in VSMCs, adventitial fibroblasts, endothelial cells, and perivascular adipocytes $[18,230,231]$. In the cells of the vascular system, the structure of NOX2 complex is similar to that found in phagocytes. However, in some conditions, NOX organizer protein 1 (NOXO1) and NOX activator protein 1 (NOXA1) may play a role in the activation of NOX2 complex [232]. NOX2 is implicated in proliferation and vascular endothelial growth factor- (VEGF-) induced migration [233] and in the regulation of the expression of adhesion molecules during inflammation and angiogenesis.

Recent studies suggest that NOX2 activation is involved in atherosclerosis [234-236]. Several experimental studies showed an upregulation of the NOX2 in the atheroma from carotid [237-239] and coronary sites [240, 241]. In an experimental model of carotid lesion induced by flow cessation, the overexpression of the NOX subunit p22phox led to a progression of carotid artery lesions, which was more marked compared to lesions in wild-type mice [242]. In atherosclerotic coronary arteries, p22phox was overexpressed in the neointimal and medial smooth cells and in infiltrating macrophages in hypercellular regions at the border of atheromatous plaques [243]. Furthermore, enhanced superoxide production was detected in coronary arteries from patients with coronary heart disease in association with upregulation of p22phox and NOX2 suggesting that both these subunits contribute to oxidative stress in human coronary atherosclerotic lesions [244]. Endothelial cells produce $\mathrm{O}_{2}{ }^{-}$prevalently via different NOX isoforms such as NOX1, NOX2, NOX4, and NOX5, which may contribute to modulate arterial dilatation with different mechanisms [245, 246]. Flow-mediated dilatation (FMD), which is dependent upon endothelial release of $\mathrm{NO}$ and is considered a surrogate marker of atherosclerosis [29], has been evaluated in patients with NOX2 (Xlinked CGD) [30] or p47phox hereditary deficiency. Patients with NOX2 and p47phox hereditary deficiency showed enhanced FMD, which, however, was more marked in NOX2-deficient patients suggesting a relationship between rate of ROS formation and artery vasoconstriction [30-32]. In accordance with these studies, compared to controls, higher values of FMD were found in carriers of hereditary deficiency of NOX2, suggesting that also a partial reduction of NOX2 can contribute to increase endothelial function [247]. The mechanism accounting for enhanced artery dilatation was attributed to heightened NO generation, which was also suggested to account for enhanced vasodilation detected in animal knockout for NOX2 [248, 249]. The evidence that the intravenous injection of L-NAME, an inhibitor of NO synthase, is able to blunt the increase of the FMD in patients with X-linked CGD [32] also confirms this 
hypothesis. The close relationship between endothelial dysfunction and NOX2 has been also studied in other models including dyslipidemia, obesity, smoking [250, 251], hypertension, metabolic syndrome, diabetes mellitus, peripheral arterial disease [252], and obstructive sleep apnea [253]. These classic cardiovascular risk factors provoke endothelial dysfunction even in childhood, and the coexistence of NOX2 regulation suggests this enzyme as a potential trigger [254-256]. In fact, children with hypercholesterolemia, obesity, or obstructive sleep apnea displayed NOX2 upregulation coincidentally with a reduced FMD [30,254-256]. A significant reduction of carotid intima-media thickness (IMT) [30], which is a surrogate marker of atherosclerosis, has been detected by Doppler ultrasonography [257] in children [30] with CGD and later confirmed in an adult cohort of female carriers with NOX2 deficiency [247]. The same evidence was then confirmed using a more sophisticated diagnostic approach, that is, magnetic resonance imaging and computed tomography, which showed that CGD patients, compared with control subjects, had a $22 \%$ lower internal carotid artery wall volume with a similar reduction detected in both the p47phox- and NOX2-deficient subtypes [258]. Based on the above-reported experimental and clinical data, NOX2 could be suggested as potential target to counteract the process of atherothrombosis; however, interventional studies with NOX2 inhibitors are warranted to assess the clinical validity of this therapeutic approach in patients at risk or with cardiovascular events. Apart from NOX2, also NOX4, NOX5, p22phox, and, to a lesser extent, NOX1 may be implicated in the pathogenesis of atherosclerosis [234, 259]. In particular, similarly to NOX2, NOX1 seems to be implicated in the acute response to injury or to angiotensin II stimulation. On the contrary, NOX4 seems to be able to maintain VSMC in a quiescent status [237]. For this reason, the association of high levels of NOX2 and low levels of NOX4 may lead to the development of intimal hyperplasia, remodelling, and accelerated atherosclerosis in vein grafts [260]. NOX5 is also overexpressed in coronary artery obtained from patients with coronary artery disease [261]. The increase of NADPH oxidase activity may also contribute to the development of atherosclerosis through lipid oxidation.

NADPH oxidase is also implicated in the pathogenesis of hypertension. Angiotensin II, which plays a critical role in the pathogenesis of hypertension, is able to induce the expression of different NOX homologues, including NOX1, NOX2, NOX4, and p22phox $[26,233,262]$. The induction of the NOX by angiotensin II increases the production of superoxide and $\mathrm{H}_{2} \mathrm{O}_{2}$ in VSMC, also leading to vascular hypertrophy. In a mouse model of p47phox deficiency, angiotensin II was not able to induce an increase of the production of $\mathrm{O}_{2}^{-}$, different from what was observed in wildtype mouse [263] suggesting that p47phox deficiency is able to attenuate angiotensin II-induced hypertension [264] and endothelial dysfunction [265]. Deletion of p47phox was also associated with the prevention of angiotensin II-induced aneurysm formation [266-268] and myocardial infarctioninduced cardiac dysfunction [263]. p47phox deficiency is able to impair both NOX1 and NOX2 activation. Overexpression in VSMC of NOX1 and p22phox in mouse has been associated with elevation of blood pressure in response to angiotensin II and with the development of vascular hypertrophy [269-271]. On the other hand, the deletion of both the subunit has a protective role against the development of endothelial dysfunction, oxidative stress, vascular hypertrophy, and aortic dissection [248, 272-274]. NOX2 is implicated in the development of vascular hypertrophy [275] and endothelial dysfunction [276], but it does not seem to be directly implicated in the regulation of blood pressure [275]. NOX4 overexpression in endothelial cells is associated with vasodilatation and reduced blood pressure, suggesting that it has a protective role in hypertension and the related complications [277]. Evidence suggest that NOX4 may have a protective role in ischemic and hypertensive stress [278]. However, studies in the brain suggest that NOX4 contributes to the oxidative stress in the context of stoke or other pathologic conditions [279].

NOX1 and NOX4 are also implicated in the pathogenesis of long-term macrovascular complications in diabetic patients [280]. Hyperglycaemia is able to directly induce the $\mathrm{NADPH}$ oxidase leading to increased ROS production and eventually to endothelial dysfunction [281].

Vascular NADPH oxidase also plays an important role in tumour growth [282] and ischemic revascularization [283]. In particular, NOX2 is implicated in endothelial cell migration [283] and NOX1, NOX4, and NOX5 are implicated in angiogenesis and neovascularization [284]. NADPH oxidase may be activated by different proangiogenic factors [285], including VEGF [286], and in turn can modulate the release of different angiogenesis-related factors, including VEGF-A [287], hypoxia-induced factor 1a (HIF-1a) [288], and matrix metalloproteinases (MMPs) [289, 290].

In pulmonary artery smooth muscle cells (PASMCs), NOX2 and NOX4 are involved in the development of pulmonary hypertension in response to chronic hypoxia [291, 292]. In particular, in response to hypoxia, the ROS produced by NOX2 activate NOX4 which in turn is able to bind HIF- $1 \alpha$, leading to PASMC proliferation [285, 292].

Finally, NOX1, NOX2, and NOX5 are also implicated in the regulation of the expression of the endothelial adhesion molecules, including vascular cell adhesion molecule 1 (VCAM-1), intercellular adhesion molecule 1 (ICAM-1), and $\mathrm{P}$ - and E-selectins. The increased expression of these molecules leads to transmigration of leukocytes into the subendothelial space [293] which is implicated in early atherosclerosis [294-296] or hypertensive vascular dysfunction [297].

\section{Hematopoietic Stem Cell Transplantation for the Treatment of CGD}

To date, hematopoietic stem cell transplantation (HSCT) represents the only available potentially curative treatment for patients with CGD of any genetic origin. In the last decade, improvements in HSCT protocols led to a significant improvement of the survival of patients with X-linked CGD (Figure 4). Currently, the two most common conditioning regimens include reduced intensity conditioning (RIC), 


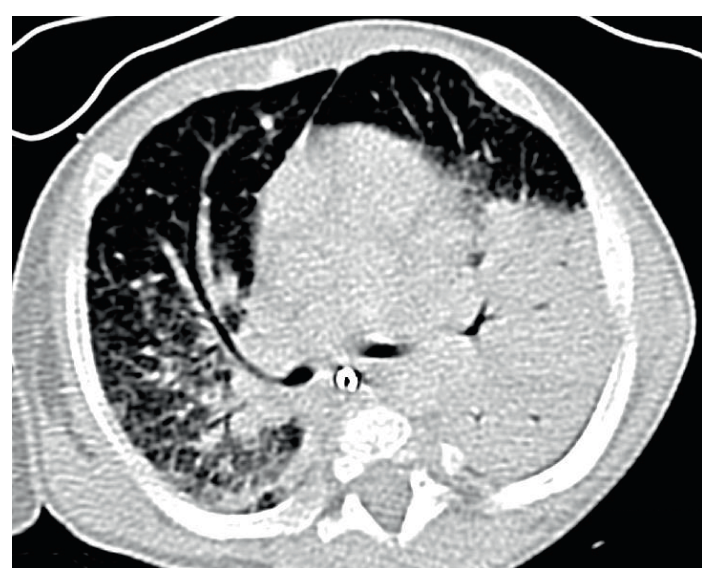

(a)

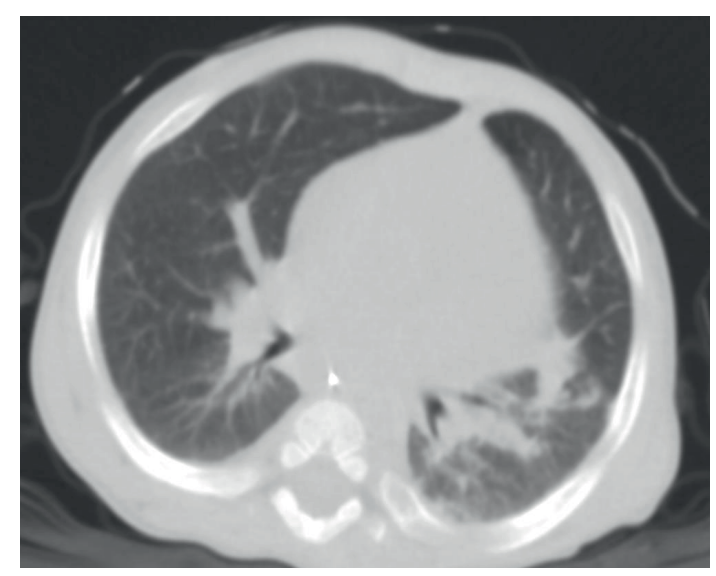

(b)

FIgURE 4: CT scan of a possible invasive fungal infection in a 5-month-old XCGD patient (a) pre-HSCT and (b) after HSCT. A progressive improvement of the areas of consolidation in the left and right lungs, especially for the right lobes, is observed. Residual pulmonary lesions are visible in the left and right inferior lobe.

typically busulfan based or a reduced toxicity regimen (typically treosulfan based). Both of them have resulted in an extremely improved survival (>90\%) [298-301]. These encouraging results corroborate the priority to extend the HSCT indications. In 2014, Güngör et al. published the largest prospective study of a reduced intensity conditioning regimen for HSCT in pediatric and adult patients with CGD [300]. In this study, HSCT was only considered in patients with more than one life-threatening infection, no compliance with antimicrobial prophylaxis, or steroid-dependent autoinflammation [300]. However, other studies showed an impressive lower survival rate in patients with $\mathrm{X}$-linked CGD treated conventionally with antibiotic and antifungal prophylaxis as compared with patients treated with HSCT [302]. In fact, patients surviving childhood face a high mortality due to a cumulative organ injury that could also dramatically affect HSCT outcome or even preclude this treatment [303]. For this reason, current clinical management of these fragile patients suggests that HSCT should be considered as a reasonable curative treatment for a wider group of patients as soon as possible and, when possible, before the onset of severe complications [302]. Apart from preexisting comorbidities and organ dysfunction, standard myeloablative conditioning protocols were also responsible for the striking transplant-related mortality observed in the past. Granulocyte infusions and more recently the use of pioglitazone, that can bypass the inability of NADPH oxidase complex by increasing mitochondrial reactive oxygen species, suggest relevant insights in the treatment of this rare disease $[304,305]$.

\section{Gene Therapy for the Treatment of X-Linked CGD}

The evidence of the high success rate of early HSCT in patients with CGD [201, 300, 306, 307] has opened the way to gene therapy (GT) approach for patients without a matched donor. A protocol based on $\gamma$ retrovirus $(\gamma \mathrm{RV})$ GT without conditioning was developed and resulted in transitory functional correction of $\leq 0.5 \%$ of peripheral blood granulocytes, without any long-term clinical benefit $[308,309]$. The main reasons of the failure of this approach were the lack of survival advantage of the transduced neutrophils over the defective ones, their short lifespan, and the inflammatory bone marrow milieu, with a potential negative effect on HSC gene transfer [310-312]. Subsequent trials with $\gamma \mathrm{RV}$ vector-transduced, mobilized CD34+ cells were attempted between 2000 and $2010[306,311,313,314]$. However, in most of the cases, a loss of the long-term engraftment of transduced cells [315] was observed. Moreover, this approach was also complicated by the occurrence of myelodysplasia and clonal expansion in both adult and pediatric patients. The safety concern led to the clinical use of regulated SIN-lentiviral vectors targeting NOX2 expression in myeloid cells. In vitro and in vivo murine studies showed that this vector is able to restore NADPH oxidase activity and has a safer profile [316]. This vector is currently employed in multicenter trials in Europe and in the USA (NCT01906541, NCT01855685, and NCT02234934).

\section{Conclusions and Perspective}

Loss-of-function mutations in genes encoding for various NADPH oxidase subunits lead to a phenotype mainly characterized by severe and recurrent infections. However, recent evidence shows that NADPH oxidase is also implicated in the regulation of several diverse mechanisms. The aim of this review is to focus on the most recent evidence regarding the biological role of NADPH oxidase and its implication in the typical CGD clinical manifestations, as well as in the more recently defined clinical features, including autoinflammatory manifestations. The identification of the pathogenic mechanisms underlying inflammatory complications has led to the identification of novel potential curative and symptomatic approaches, whose effectiveness in vitro and in vivo has been explored in some preliminary models and clinical trials. New biological roles of NADPH oxidase are emerging, that is, the implication in the pathogenesis of atherosclerosis. 
These observations are paving the way for future observational and interventional studies on CGD-affected patients and carriers.

\section{Conflicts of Interest}

The authors declare no conflicts of interest.

\section{References}

[1] A. Panday, M. K. Sahoo, D. Osorio, and S. Batra, "NADPH oxidases: an overview from structure to innate immunityassociated pathologies," Cellular and Molecular Immunology, vol. 12, no. 1, pp. 5-23, 2015.

[2] A. W. Segal, R. Garcia, H. Goldstone, A. R. Cross, and O. T. Jones, "Cytochrome $\mathrm{b}_{-245}$ of neutrophils is also present in human monocytes, macrophages and eosinophils," Biochemical Journal, vol. 196, no. 1, pp. 363-367, 1981.

[3] S. Elsen, J. Doussière, C. L. Villiers et al., "Cryptic $\mathrm{O}_{2}^{-}$-generating NADPH oxidase in dendritic cells," Journal of Cell Science, vol. 117, no. 11, pp. 2215-2226, 2004.

[4] D. B. Graham, L. M. Stephenson, S. K. Lam et al., "An ITAMsignaling pathway controls cross-presentation of particulate but not soluble antigens in dendritic cells," The Journal of Experimental Medicine, vol. 204, no. 12, pp. 2889-2897, 2007.

[5] A. R. Mantegazza, A. Savina, M. Vermeulen et al., "NADPH oxidase controls phagosomal $\mathrm{pH}$ and antigen crosspresentation in human dendritic cells," Blood, vol. 112, no. 12, pp. 4712-4722, 2008.

[6] A. Savina, C. Jancic, S. Hugues et al., "NOX2 controls phagosomal $\mathrm{pH}$ to regulate antigen processing during crosspresentation by dendritic cells," Cell, vol. 126, no. 1, pp. 205-218, 2006.

[7] B. H. Segal, P. Veys, H. Malech, and M. J. Cowan, "Chronic granulomatous disease: lessons from a rare disorder," Biology of Blood and Marrow Transplantation, vol. 17, no. 1, Supplement, pp. S123-S131, 2011.

[8] B. E. Marciano, S. D. Rosenzweig, D. E. Kleiner et al., "Gastrointestinal involvement in chronic granulomatous disease," Pediatrics, vol. 114, no. 2, pp. 462-468, 2004.

[9] S. O’Neill, J. Brault, M.-J. Stasia, and U. G. Knaus, "Genetic disorders coupled to ROS deficiency," Redox Biology, vol. 6, pp. 135-156, 2015.

[10] S. S. De Ravin, N. Naumann, M. R. Robinson et al., "Sarcoidosis in chronic granulomatous disease," Pediatrics, vol. 117, no. 3, pp. e590-e595, 2006.

[11] B. H. Segal, M. J. Grimm, A. N. H. Khan, W. Han, and T. S. Blackwell, "Regulation of innate immunity by NADPH oxidase," Free Radical Biology \& Medicine, vol. 53, no. 1, pp. 72-80, 2012.

[12] F. Meissner, R. A. Seger, D. Moshous, A. Fischer, J. Reichenbach, and A. Zychlinsky, "Inflammasome activation in NADPH oxidase defective mononuclear phagocytes from patients with chronic granulomatous disease," Blood, vol. 116, no. 9, pp. 1570-1573, 2010.

[13] F. L. van de Veerdonk, S. P. Smeekens, L. A. B. Joosten et al., "Reactive oxygen species-independent activation of the IL$1 \beta$ inflammasome in cells from patients with chronic granulomatous disease," Proceedings of the National Academy of Sciences of the United States of America, vol. 107, no. 7, pp. 3030-3033, 2010.
[14] K. J. Hahn, N. Ho, L. Yockey et al., "Treatment with anakinra, a recombinant IL-1 receptor antagonist, unlikely to induce lasting remission in patients with CGD colitis," The American Journal of Gastroenterology, vol. 110, no. 6, pp. 938-939, 2015.

[15] A. de Luca, S. P. Smeekens, A. Casagrande et al., "IL-1 receptor blockade restores autophagy and reduces inflammation in chronic granulomatous disease in mice and in humans," Proceedings of the National Academy of Sciences of the United States of America, vol. 111, no. 9, pp. 3526-3531, 2014.

[16] Y. C. Kim and K.-L. Guan, "mTOR: a pharmacologic target for autophagy regulation," The Journal of Clinical Investigation, vol. 125, no. 1, pp. 25-32, 2015.

[17] A. Gabrion, I. Hmitou, D. Moshous et al., "Mammalian target of rapamycin inhibition counterbalances the inflammatory status of immune cells in patients with chronic granulomatous disease," The Journal of Allergy and Clinical Immunology, vol. 139, no. 5, pp. 1641-1649.e6, 2017.

[18] J. D. Van Buul, M. Fernandez-Borja, E. C. Anthony, and P. L. Hordijk, "Expression and localization of NOX2 and NOX4 in primary human endothelial cells," Antioxidants \& Redox Signaling, vol. 7, no. 3-4, pp. 308-317, 2005.

[19] P. A. Krijnen, C. Meischl, C. E. Hack et al., "Increased Nox2 expression in human cardiomyocytes after acute myocardial infarction," Journal of Clinical Pathology, vol. 56, no. 3, pp. 194-199, 2003.

[20] C. Piccoli, A. D’Aprile, M. Ripoli et al., "Bone-marrow derived hematopoietic stem/progenitor cells express multiple isoforms of NADPH oxidase and produce constitutively reactive oxygen species," Biochemical and Biophysical Research Communications, vol. 353, no. 4, pp. 965-972, 2007.

[21] C. Piccoli, R. Ria, R. Scrima et al., "Characterization of mitochondrial and extra-mitochondrial oxygen consuming reactions in human hematopoietic stem cells. Novel evidence of the occurrence of NAD(P)H oxidase activity," Journal of Biological Chemistry, vol. 280, no. 28, pp. 26467-26476, 2005.

[22] F. Violi and P. Pignatelli, "Clinical application of NOX activity and other oxidative biomarkers in cardiovascular disease: a critical review," Antioxidants \& Redox Signaling, vol. 23, no. 5, pp. 514-532, 2014.

[23] M. W. Ma, J. Wang, Q. Zhang et al., "NADPH oxidase in brain injury and neurodegenerative disorders," Molecular Neurodegeneration, vol. 12, no. 1, p. 7, 2017.

[24] J. D. Lambeth, "Nox enzymes, ROS, and chronic disease: an example of antagonistic pleiotropy," Free Radical Biology \& Medicine, vol. 43, no. 3, pp. 332-347, 2007.

[25] C. E. Murdoch, S. Chaubey, L. Zeng et al., "Endothelial NADPH oxidase- 2 promotes interstitial cardiac fibrosis and diastolic dysfunction through proinflammatory effects and endothelial-mesenchymal transition," Journal of the American College of Cardiology, vol. 63, no. 24, pp. 27342741, 2014.

[26] S. Rajagopalan, S. Kurz, T. Münzel et al., "Angiotensin II-mediated hypertension in the rat increases vascular superoxide production via membrane NADH/NADPH oxidase activation. Contribution to alterations of vasomotor tone," The Journal of Clinical Investigation, vol. 97, no. 8, pp. 1916-1923, 1996.

[27] H. Mollnau, M. Wendt, K. Szöcs et al., "Effects of angiotensin II infusion on the expression and function of NAD(P)H oxidase and components of nitric oxide/cGMP signaling," Circulation Research, vol. 90, no. 4, pp. 58e-565, 2002. 
[28] C. E. Murdoch, S. P. Alom-Ruiz, M. Wang et al., "Role of endothelial Nox2 NADPH oxidase in angiotensin II-induced hypertension and vasomotor dysfunction," Basic Research in Cardiology, vol. 106, no. 4, pp. 527-538, 2011.

[29] D. H. J. Thijssen, M. A. Black, K. E. Pyke et al., “Assessment of flow-mediated dilation in humans: a methodological and physiological guideline," American Journal of Physiology Heart and Circulatory Physiology, vol. 300, no. 1, pp. H2H12, 2011.

[30] F. Violi, V. Sanguigni, R. Carnevale et al., "Hereditary deficiency of gp $91^{\text {phox }}$ is associated with enhanced arterial dilatation: results of a multicenter study," Circulation, vol. 120, no. 16, pp. 1616-1622, 2009.

[31] L. Loffredo, R. Carnevale, V. Sanguigni et al., "Does NADPH oxidase deficiency cause artery dilatation in humans?," Antioxidants \& Redox Signaling, vol. 18, no. 12, pp. 1491-1496, 2012.

[32] F. Violi, V. Sanguigni, L. Loffredo et al., "Nox2 is determinant for ischemia-induced oxidative stress and arterial vasodilatation: a pilot study in patients with hereditary Nox2 deficiency," Arteriosclerosis, Thrombosis, and Vascular Biology, vol. 26, no. 8, pp. e131-e132, 2006.

[33] K. Bedard and K.-H. Krause, "The NOX family of ROSgenerating NADPH oxidases: physiology and pathophysiology," Physiological Reviews, vol. 87, no. 1, pp. 245-313, 2007.

[34] J. D. Lambeth and A. S. Neish, "Nox enzymes and new thinking on reactive oxygen: a double-edged sword revisited," Annual Review of Pathology: Mechanisms of Disease, vol. 9, pp. 119-145, 2014.

[35] M. Muzza and L. Fugazzola, "Disorders of $\mathrm{H}_{2} \mathrm{O}_{2}$ generation," Best Practice \& Research Clinical Endocrinology \& Metabolism, vol. 31, no. 2, pp. 225-240, 2017.

[36] G. R. Drummond, S. Selemidis, K. K. Griendling, and C. G. Sobey, "Combating oxidative stress in vascular disease: NADPH oxidases as therapeutic targets," Nature Reviews Drug Discovery, vol. 10, no. 6, pp. 453-471, 2011.

[37] T. L. Leto, S. Morand, D. Hurt, and T. Ueyama, "Targeting and regulation of reactive oxygen species generation by Nox family NADPH oxidases," Antioxidants \& Redox Signaling, vol. 11, no. 10, pp. 2607-2619, 2009.

[38] P. V. Vignais, "The superoxide-generating NADPH oxidase: structural aspects and activation mechanism," Cellular and Molecular Life Sciences CMLS, vol. 59, no. 9, pp. 1428-1459, 2002.

[39] F. R. DeLeo, J. Renee, S. McCormick et al., "Neutrophils exposed to bacterial lipopolysaccharide upregulate NADPH oxidase assembly," The Journal of Clinical Investigation, vol. 101, no. 2, pp. 455-463, 1998.

[40] L. Yu, M. T. Quinn, A. R. Cross, and M. C. Dinauer, "Gp91" phox is the heme binding subunit of the superoxidegenerating NADPH oxidase," Proceedings of the National Academy of Sciences of the United States of America, vol. 95, no. 14, pp. 7993-7998, 1998.

[41] A. W. Segal, I. West, F. Wientjes et al., "Cytochrome $b_{-245}$ is a flavocytochrome containing FAD and the NADPH-binding site of the microbicidal oxidase of phagocytes," Biochemical Journal, vol. 284, no. 3, pp. 781-788, 1992.

[42] H. Sumimoto, N. Sakamoto, M. Nozaki, Y. Sakaki, $\mathrm{K}$. Takeshige, and S. Minakami, "Cytochrome $b_{558}$, a component of the phagocyte NADPH oxidase, is a flavoprotein,"
Biochemical and Biophysical Research Communications, vol. 186, no. 3, pp. 1368-1375, 1992.

[43] D. Rotrosen, C. L. Yeung, T. L. Leto, H. L. Malech, and C. H. Kwong, "Cytochrome b558: the flavin-binding component of the phagocyte NADPH oxidase," Science, vol. 256, no. 5062, pp. 1459-1462, 1992.

[44] S. S. Iyer, D. W. Pearson, W. M. Nauseef, and R. A. Clark, "Evidence for a readily dissociable complex of p47phox and p67phox in cytosol of unstimulated human neutrophils," Journal of Biological Chemistry, vol. 269, no. 35, pp. 2240522411, 1994.

[45] J. W. Park, J. E. Benna, K. E. Scott, B. L. Christensen, S. J. Chanock, and B. M. Babior, "Isolation of a complex of respiratory burst oxidase components from resting neutrophil cytosol," Biochemistry, vol. 33, no. 10, pp. 2907-2911, 1994.

[46] K. Lapouge, S. J. Smith, Y. Groemping, and K. Rittinger, "Architecture of the p40-p47-p67 ${ }^{\text {phox }}$ complex in the resting state of the NADPH oxidase. A central role for p67 ${ }^{\text {phox }}$," Journal of Biological Chemistry, vol. 277, no. 12, pp. 10121-10128, 2002.

[47] Y. Groemping and K. Rittinger, "Activation and assembly of the NADPH oxidase: a structural perspective," Biochemical Journal, vol. 386, no. 3, pp. 401-416, 2005.

[48] Y. Groemping, K. Lapouge, S. J. Smerdon, and K. Rittinger, "Molecular basis of phosphorylation-induced activation of the NADPH oxidase," Cell, vol. 113, no. 3, pp. 343-355, 2003.

[49] S. Tsunawaki and K. Yoshikawa, "Relationships of p40phox with p67phox in the activation and expression of the human respiratory burst NADPH oxidase," The Journal of Biochemistry, vol. 128, no. 5, pp. 777-783, 2000.

[50] T. Ago, F. Kuribayashi, H. Hiroaki et al., "Phosphorylation of $\mathrm{p} 47^{\text {phox }}$ directs phox homology domain from SH3 domain toward phosphoinositides, leading to phagocyte NADPH oxidase activation," Proceedings of the National Academy of Sciences of the United States of America, vol. 100, no. 8, pp. 4474-4479, 2003.

[51] M. Takahashi, T. J. Dillon, C. Liu, Y. Kariya, Z. Wang, and P. J. Stork, "Protein kinase A-dependent phosphorylation of Rap1 regulates its membrane localization and cell migration," Journal of Biological Chemistry, vol. 288, no. 39, pp. 2771227723, 2013.

[52] S. Grizot, J. Faure, F. Fieschi, P. V. Vignais, M. C. Dagher, and E. Pebay-Peyroula, "Crystal structure of the Rac1-RhoGDI complex involved in NADPH oxidase activation," Biochemistry, vol. 40, no. 34, pp. 10007-10013, 2001.

[53] P. G. Heyworth, U. G. Knaus, J. Settleman, J. T. Curnutte, and G. M. Bokoch, "Regulation of NADPH oxidase activity by Rac GTPase activating protein(s)," Molecular Biology of the Cell, vol. 4, no. 11, pp. 1217-1223, 1993.

[54] S. Dusi, M. Donini, and F. Rossi, "Mechanisms of NADPH oxidase activation: translocation of $\mathrm{p} 40_{\text {phox }}$, Rac1 and Rac2 from the cytosol to the membranes in human neutrophils lacking p47 $47_{\text {hox }}$ or p67 phox'" Biochemical Journal, vol. 314, no. 2, pp. 409-412, 1996.

[55] E. Pick, "Role of the Rho GTPase Rac in the activation of the phagocyte NADPH oxidase: outsourcing a key task," Small GTPases, vol. 5, article e27952, 2014.

[56] G. M. Bokoch and C. A. Parkos, "Identification of novel GTPbinding proteins in the human neutrophil," FEBS Letters, vol. 227 , no. 1, pp. 66-70, 1988. 
[57] M. T. Quinn, C. A. Parkos, L. Walker, S. H. Orkin, M. C. Dinauer, and A. J. Jesaitis, "Association of a Ras-related protein with cytochrome $b$ of human neutrophils," Nature, vol. 342, no. 6246, pp. 198-200, 1989.

[58] L. A. Quilliam, H. Mueller, B. P. Bohl et al., "Rap1A is a substrate for cyclic AMP-dependent protein kinase in human neutrophils," The Journal of Immunology, vol. 147, no. 5, pp. 1628-1635, 1991.

[59] T. G. Gabig, C. D. Crean, P. L. Mantel, and R. Rosli, "Function of wild-type or mutant Rac2 and Rapla GTPases in differentiated HL60 cell NADPH oxidase activation," Blood, vol. 85, no. 3, pp. 804-811, 1995.

[60] F. E. Maly, L. A. Quilliam, O. Dorseuil, C. J. Der, and G. M. Bokoch, "Activated or dominant inhibitory mutants of Rap1A decrease the oxidative burst of Epstein-Barr virustransformed human B lymphocytes," Journal of Biological Chemistry, vol. 269, no. 29, pp. 18743-18746, 1994.

[61] M. T. Quinn, M. L. Mullen, A. J. Jesaitis, and J. G. Linner, "Subcellular distribution of the Rap1A protein in human neutrophils: colocalization and cotranslocation with cytochrome b559," Blood, vol. 79, no. 6, pp. 1563-1573, 1992.

[62] Y. Li, J. Yan, P. De et al., "Rap1a null mice have altered myeloid cell functions suggesting distinct roles for the closely related Rapla and $1 \mathrm{~b}$ proteins," The Journal of Immunology, vol. 179, no. 12, pp. 8322-8331, 2007.

[63] J. L. Freeman and J. D. Lambeth, "NADPH oxidase activity is independent of $47^{\text {phox }}$ in vitro," The Journal of Biological Chemistry, vol. 271, no. 37, pp. 22578-22582, 1996.

[64] V. Koshkin, O. Lotan, and E. Pick, "The cytosolic component $\mathrm{p} 47^{\text {phox }}$ is not a sine qua non participant in the activation of NADPH oxidase but is required for optimal superoxide production," Journal of Biological Chemistry, vol. 271, no. 48, pp. 30326-30329, 1996.

[65] A. R. Cross, R. W. Erickson, and J. T. Curnutte, "Simultaneous presence of $\mathrm{p} 47^{\text {phox }}$ and flavocytochrome $b_{-245}$ are required for the activation of NADPH oxidase by anionic amphiphiles. Evidence for an intermediate state of oxidase activation," Journal of Biological Chemistry, vol. 274, no. 22, pp. 15519-15525, 1999.

[66] M. L. Kreck, J. L. Freeman, A. Abo, and J. D. Lambeth, "Membrane association of Rac is required for high activity of the respiratory burst oxidase," Biochemistry, vol. 35, no. 49, pp. 15683-15692, 1996.

[67] Y. Gorzalczany, N. Sigal, M. Itan, O. Lotan, and E. Pick, “Targeting of Racl to the phagocyte membrane is sufficient for the induction of NADPH oxidase assembly," Journal of Biological Chemistry, vol. 275, no. 51, pp. 40073-40081, 2000.

[68] Y. Gorzalczany, N. Alloul, N. Sigal, C. Weinbaum, and E. Pick, "A prenylated $\mathrm{p} 67^{\text {phox }}$-Rac1 chimera elicits NADPHdependent superoxide production by phagocyte membranes in the absence of an activator and of $\mathrm{p} 47^{\text {phox }}$ : conversion of a pagan NADPH oxidase to monotheism," Journal of Biological Chemistry, vol. 277, no. 21, pp. 18605-18610, 2002.

[69] C. H. Han, J. L. Freeman, T. Lee, S. A. Motalebi, and J. D. Lambeth, "Regulation of the neutrophil respiratory burst oxidase. Identification of an activation domain in p67 phox," Journal of Biological Chemistry, vol. 273, no. 27, pp. 1666316668, 1998.

[70] H. Sumimoto, "Structure, regulation and evolution of Noxfamily NADPH oxidases that produce reactive oxygen species," The FEBS Journal, vol. 275, no. 13, pp. 32493277, 2008.
[71] A. P. Levine, M. R. Duchen, S. de Villiers, P. R. Rich, and A. W. Segal, "Alkalinity of neutrophil phagocytic vacuoles is modulated by HVCN1 and has consequences for myeloperoxidase activity," PLoS One, vol. 22, no. 6, article e0125906, 2015.

[72] E. P. Reeves, H. Lu, H. L. Jacobs et al., "Killing activity of neutrophils is mediated through activation of proteases by $\mathrm{K}^{+}$flux," Nature, vol. 416, no. 6878, pp. 291-297, 2002.

[73] Y. A. Suh, R. S. Arnold, B. Lassegue et al., "Cell transformation by the superoxide-generating oxidase Mox1," Nature, vol. 401, no. 6748, pp. 79-82, 1999.

[74] R. K. Ambasta, P. Kumar, K. K. Griendling, H. H. Schmidt, R. Busse, and R. P. Brandes, "Direct interaction of the novel Nox proteins with p22phox is required for the formation of a functionally active NADPH oxidase," Journal of Biological Chemistry, vol. 279, no. 44, pp. 45935-45941, 2004.

[75] R. M. Jones, L. Luo, C. S. Ardita et al., "Symbiotic lactobacilli stimulate gut epithelial proliferation via Nox-mediated generation of reactive oxygen species," The EMBO Journal, vol. 32, no. 23, pp. 3017-3028, 2013.

[76] G. Leoni, A. Alam, P. A. Neumann et al., “Annexin A1, formyl peptide receptor, and NOX1 orchestrate epithelial repair," The Journal of Clinical Investigation, vol. 123, no. 1, pp. 443-454, 2013.

[77] B. Banfi, B. Malgrange, J. Knisz, K. Steger, M. Dubois-Dauphin, and K. H. Krause, "NOX3, a superoxide-generating NADPH oxidase of the inner ear," Journal of Biological Chemistry, vol. 279, no. 44, pp. 46065-46072, 2004.

[78] G. Cheng, Z. Cao, X. Xu, E. G. van Meir, and J. D. Lambeth, "Homologs of gp91phox: cloning and tissue expression of Nox3, Nox4, and Nox5," Gene, vol. 269, no. 1-2, pp. 131140, 2001.

[79] R. Paffenholz, R. A. Bergstrom, F. Pasutto et al., "Vestibular defects in head-tilt mice result from mutations in Nox3, encoding an NADPH oxidase," Genes \& Development, vol. 18, no. 5, pp. 486-491, 2004.

[80] H. Kikuchi, M. Hikage, H. Miyashita, and M. Fukumoto, "NADPH oxidase subunit, gp91 phox homologue, preferentially expressed in human colon epithelial cells," Gene, vol. 254, no. 1-2, pp. 237-243, 2000.

[81] T. Kawahara, D. Ritsick, G. Cheng, and J. D. Lambeth, "Point mutations in the proline-rich region of $\mathrm{p} 22^{\text {phox }}$ are dominant inhibitors of Nox1- and Nox2-dependent reactive oxygen generation," Journal of Biological Chemistry, vol. 280, no. 36, pp. 31859-31869, 2005.

[82] N. Ueno, R. Takeya, K. Miyano, H. Kikuchi, and H. Sumimoto, "The NADPH oxidase Nox3 constitutively produces superoxide in a $222^{\text {phox }}$-dependent manner: its regulation by oxidase organizers and activators," Journal of Biological Chemistry, vol. 280, no. 24, pp. 23328-23339, 2005.

[83] M. Geiszt, J. B. Kopp, P. Varnai, and T. L. Leto, "Identification of Renox, an NAD(P)H oxidase in kidney," Proceedings of the National Academy of Sciences of the United States of America, vol. 97, no. 14, pp. 8010-8014, 2000.

[84] Y. Nisimoto, B. A. Diebold, D. Cosentino-Gomes, and J. D. Lambeth, "Nox4: a hydrogen peroxide-generating oxygen sensor," Biochemistry, vol. 53, no. 31, pp. 5111-5120, 2014.

[85] L. Serrander, L. Cartier, K. Bedard et al., "NOX4 activity is determined by mRNA levels and reveals a unique pattern of ROS generation," Biochemical Journal, vol. 406, no. 1, pp. 105-114, 2007. 
[86] R. S. BelAiba, T. Djordjevic, A. Petry et al., "NOX5 variants are functionally active in endothelial cells," Free Radical Biology \& Medicine, vol. 42, no. 4, pp. 446-459, 2007.

[87] B. Bánfi, G. Molnár, A. Maturana et al., "A Ca ${ }^{2+}$-activated NADPH oxidase in testis, spleen, and lymph nodes," Journal of Biological Chemistry, vol. 276, no. 40, pp. 37594-37601, 2001.

[88] C. Dupuy, R. Ohayon, A. Valent, M. S. Noel-Hudson, D. Deme, and A. Virion, "Purification of a novel flavoprotein involved in the thyroid NADPH oxidase. Cloning of the porcine and human cDNAs," Journal of Biological Chemistry, vol. 274, no. 52, pp. 37265-37269, 1999.

[89] X. De Deken, D. Wang, M. C. Many et al., "Cloning of two human thyroid cDNAs encoding new members of the NADPH oxidase family," Journal of Biological Chemistry, vol. 275, no. 30, pp. 23227-23233, 2000.

[90] M. Geiszt, J. Witta, J. Baffi, K. Lekstrom, and T. L. Leto, “Dual oxidases represent novel hydrogen peroxide sources supporting mucosal surface host defense," The FASEB Journal, vol. 17, no. 11, pp. 1502-1504, 2003.

[91] R. Forteza, M. Salathe, F. Miot, R. Forteza, and G. E. Conner, "Regulated hydrogen peroxide production by Duox in human airway epithelial cells," American Journal of Respiratory Cell and Molecular Biology, vol. 32, no. 5, pp. 462-469, 2005.

[92] R. W. Harper, C. Xu, J. P. Eiserich et al., "Differential regulation of dual NADPH oxidases/peroxidases, Duox1 and Duox2, by Th1 and Th2 cytokines in respiratory tract epithelium," FEBS Letters, vol. 579, no. 21, pp. 4911-4917, 2005.

[93] R. A. El Hassani, N. Benfares, B. Caillou et al., "Dual oxidase2 is expressed all along the digestive tract," American Journal of Physiology Gastrointestinal and Liver Physiology, vol. 288, no. 5, pp. G933-G942, 2005.

[94] W. A. Edens, L. Sharling, G. Cheng et al., "Tyrosine crosslinking of extracellular matrix is catalyzed by Duox, a multidomain oxidase/peroxidase with homology to the phagocyte oxidase subunit gp91phox," The Journal of Cell Biology, vol. 154, no. 4, pp. 879-892, 2001.

[95] K. Bedard, V. Jaquet, and K. H. Krause, "NOX5: from basic biology to signaling and disease," Free Radical Biology \& Medicine, vol. 52, no. 4, pp. 725-734, 2012.

[96] X. De Deken, B. Corvilain, J. E. Dumont, and F. Miot, "Roles of DUOX-mediated hydrogen peroxide in metabolism, host defense, and signaling," Antioxidants \& Redox Signaling, vol. 20, no. 17, pp. 2776-2793, 2014.

[97] B. Corvilain, L. Collyn, J. van Sande, and J. E. Dumont, "Stimulation by iodide of $\mathrm{H}_{2} \mathrm{O}_{2}$ generation in thyroid slices from several species," American Journal of Physiology Endocrinology and Metabolism, vol. 278, no. 4, pp. E692-E699, 2000.

[98] L. C. Cardoso, D. C. L. Martins, M. D. L. Figueiredo et al., " $\mathrm{Ca}^{2+} /$ nicotinamide adenine dinucleotide phosphatedependent $\mathrm{H} 2 \mathrm{O} 2$ generation is inhibited by iodide in human thyroids," The Journal of Clinical Endocrinology \& Metabolism, vol. 86, no. 9, pp. 4339-4343, 2001.

[99] J. D. Oram and B. Reiter, "The inhibition of streptococci by lactoperoxidase, thiocyanate and hydrogen peroxide. The oxidation of thiocyanate and the nature of the inhibitory compound," Biochemical Journal, vol. 100, no. 2, pp. 382$388,1966$.

[100] C. Gerson, J. Sabater, M. Scuri et al., "The lactoperoxidase system functions in bacterial clearance of airways," American
Journal of Respiratory Cell and Molecular Biology, vol. 22, no. 6, pp. 665-671, 2000.

[101] W. H. Clem and S. J. Klebanoff, "Inhibitory effect of saliva on glutamic acid accumulation by Lactobacillus acidophilus and the role of the lactoperoxidase-thiocyanate system," Journal of Bacteriology, vol. 91, no. 5, pp. 1848-1853, 1966.

[102] Y. Song, J. Ruf, P. Lothaire et al., "Association of Duoxes with thyroid peroxidase and its regulation in thyrocytes," The Journal of Clinical Endocrinology \& Metabolism, vol. 95, no. 1, pp. 375-382, 2010.

[103] D. Roos, D. B. Kuhns, A. Maddalena et al., "Hematologically important mutations: X-linked chronic granulomatous disease (third update)," Blood Cells, Molecules, and Diseases, vol. 45 , no. 3, pp. 246-265, 2010.

[104] D. Roos, D. B. Kuhns, A. Maddalena et al., "Hematologically important mutations: the autosomal recessive forms of chronic granulomatous disease (second update)," Blood Cells, Molecules, and Diseases, vol. 44, no. 4, pp. 291-299, 2010.

[105] J. D. Matute, A. A. Arias, N. A. M. Wright et al., "A new genetic subgroup of chronic granulomatous disease with autosomal recessive mutations in $\mathrm{p} 40^{\text {phox }}$ and selective defects in neutrophil NADPH oxidase activity," Blood, vol. 114, no. 15, pp. 3309-3315, 2009.

[106] D. R. Ambruso, C. Knall, A. N. Abell et al., "Human neutrophil immunodeficiency syndrome is associated with an inhibitory Rac2 mutation," Proceedings of the National Academy of Sciences of the United States of America, vol. 97, no. 9, pp. 4654-4659, 2000.

[107] A. G. Kurkchubasche, J. A. Panepinto, T. F. Tracy Jr., G. W. Thurman, and D. R. Ambruso, "Clinical features of a human Rac2 mutation: a complex neutrophil dysfunction disease," The Journal of Pediatrics, vol. 139, no. 1, pp. 141-147, 2001.

[108] D. Accetta, G. Syverson, B. Bonacci et al., "Human phagocyte defect caused by a Rac2 mutation detected by means of neonatal screening for T-cell lymphopenia," The Journal of Allergy and Clinical Immunology, vol. 127, no. 2, pp. 535538.e2, 2011.

[109] O. K. Alkhairy, N. Rezaei, R. R. Graham et al., " $R A C 2$ loss-offunction mutation in 2 siblings with characteristics of common variable immunodeficiency," The Journal of Allergy and Clinical Immunology, vol. 135, no. 5, pp. 1380-1384.e5, 2015.

[110] M. J. Walmsley, S. K. Ooi, L. F. Reynolds et al., "Critical roles for Rac1 and Rac2 GTPases in B cell development and signaling," Science, vol. 302, no. 5644, pp. 459-462, 2003.

[111] F. Guo, J. A. Cancelas, D. Hildeman, D. A. Williams, and Y. Zheng, "Rac GTPase isoforms Rac1 and Rac2 play a redundant and crucial role in T-cell development," Blood, vol. 112, no. 5, pp. 1767-1775, 2008.

[112] C. Dumont, A. Corsoni-Tadrzak, S. Ruf et al., "Rac GTPases play critical roles in early T-cell development," Blood, vol. 113, no. 17, pp. 3990-3998, 2009.

[113] R. B. Henderson, K. Grys, A. Vehlow et al., "A novel Racdependent checkpoint in B cell development controls entry into the splenic white pulp and cell survival," The Journal of Experimental Medicine, vol. 207, no. 4, pp. 837-853, 2010.

[114] S. Sirinavin, C. Techasaensiri, S. Benjaponpitak, R. Pornkul, and M. Vorachit, "Invasive Chromobacterium violaceum infection in children: case report and review," The Pediatric Infectious Disease Journal, vol. 24, no. 6, pp. 559-561, 2005. 
[115] T. L. Mailman and M. H. Schmidt, "Francisella philomiragia adenitis and pulmonary nodules in a child with chronic granulomatous disease," Canadian Journal of Infectious Diseases and Medical Microbiology, vol. 16, no. 4, pp. 245248, 2005.

[116] E. L. Falcone, J. R. Petts, M. B. Fasano et al., "Methylotroph infections and chronic granulomatous disease," Emerging Infectious Diseases, vol. 22, no. 3, pp. 404-409, 2016.

[117] D. E. Greenberg, A. R. Shoffner, A. M. Zelazny et al., "Recurrent Granulibacter bethesdensis infections and chronic granulomatous disease," Emerging Infectious Diseases, vol. 16, no. 9, pp. 1341-1348, 2010.

[118] F. C. López, F. F. de Luna, M. C. Delgado et al., "Granulibacter bethesdensis isolated in a child patient with chronic granulomatous disease," Journal of Infection, vol. 57, no. 3, pp. 275-277, 2008.

[119] J. M. Chase, S. M. Holland, D. E. Greenberg, K. MarshallBatty, A. M. Zelazny, and J. A. Church, “Acidomonas methanolica-associated necrotizing lymphadenitis in a patient with chronic granulomatous disease," Journal of Clinical Immunology, vol. 32, no. 6, pp. 1193-1196, 2012.

[120] C. C. Lai, A. Cheng, W. L. Liu et al., "Infections caused by unusual Methylobacterium species," Journal of Clinical Microbiology, vol. 49, no. 9, pp. 3329-3331, 2011.

[121] J. Reichenbach, U. Lopatin, N. Mahlaoui et al., “Actinomyces in chronic granulomatous disease: an emerging and unanticipated pathogen," Clinical Infectious Diseases, vol. 49, no. 11, pp. 1703-1710, 2009.

[122] L. B. K. R. Jones, P. McGrogan, T. J. Flood et al., "Special article: chronic granulomatous disease in the United Kingdom and Ireland: a comprehensive national patient-based registry," Clinical \& Experimental Immunology, vol. 152, no. 2, pp. 211-218, 2008.

[123] J. Liese, S. Kloos, V. Jendrossek et al., "Long-term follow-up and outcome of 39 patients with chronic granulomatous disease," The Journal of Pediatrics, vol. 137, no. 5, pp. 687693, 2000.

[124] J. A. Winkelstein, M. C. Marino, R. B. Johnston Jr. et al., "Chronic granulomatous disease: report on a national registry of 368 patients," Medicine, vol. 79, no. 3, pp. 155-169, 2000.

[125] J. M. van den Berg, E. van Koppen, A. Ahlin et al., "Chronic granulomatous disease: the European experience," PLoS One, vol. 4, no. 4, article e5234, 2009.

[126] B. Martire, R. Rondelli, A. Soresina et al., "Clinical features, long-term follow-up and outcome of a large cohort of patients with chronic granulomatous disease: an Italian multicenter study," Clinical Immunology, vol. 126, no. 2, pp. 155164, 2008.

[127] B. Wolach, R. Gavrieli, M. de Boer et al., "Chronic granulomatous disease: clinical, functional, molecular, and genetic studies. The Israeli experience with 84 patients," American Journal of Hematology, vol. 92, no. 1, pp. 28-36, 2017.

[128] E. B. de Oliveira-Junior, N. B. Zurro, C. Prando et al., "Clinical and genotypic spectrum of chronic granulomatous disease in 71 Latin American patients: first report from the LASID registry," Pediatric Blood \& Cancer, vol. 62, no. 12, pp. 2101-2107, 2015.

[129] M. C. B. Godoy, P. M. Vos, P. L. Cooperberg, C. P. Lydell, P. Phillips, and N. L. Müller, "Chest radiographic and CT manifestations of chronic granulomatous disease in adults,"
American Journal of Roentgenology, vol. 191, no. 5, pp. 1570-1575, 2008.

[130] D. E. Greenberg, J. B. Goldberg, F. Stock, P. R. Murray, S. M. Holland, and J. J. Lipuma, "Recurrent Burkholderia infection in patients with chronic granulomatous disease: 11-year experience at a large referral center," Clinical Infectious Diseases, vol. 48, no. 11, pp. 1577-1579, 2009.

[131] S. E. Dorman, S. V. Guide, P. S. Conville et al., "Nocardia infection in chronic granulomatous disease," Clinical Infectious Diseases, vol. 35, no. 4, pp. 390-394, 2002.

[132] F. Conti, S. O. Lugo-Reyes, L. Blancas Galicia et al., "Mycobacterial disease in patients with chronic granulomatous disease: a retrospective analysis of 71 cases," The Journal of Allergy and Clinical Immunology, vol. 138, no. 1, pp. 241248.e3, 2016.

[133] P. P. W. Lee, K.-W. Chan, L. Jiang et al., "Susceptibility to mycobacterial infections in children with X-linked chronic granulomatous disease: a review of 17 patients living in a region endemic for tuberculosis," The Pediatric Infectious Disease Journal, vol. 27, no. 3, pp. 224-230, 2008.

[134] S. Siddiqui, V. L. Anderson, D. M. Hilligoss et al., "Fulminant mulch pneumonitis: an emergency presentation of chronic granulomatous disease," Clinical Infectious Diseases, vol. 45, no. 6, pp. 673-681, 2007.

[135] O. A. Cornely, A. Bohme, D. Buchheidt et al., "Primary prophylaxis of invasive fungal infections in patients with hematologic malignancies. Recommendations of the Infectious Diseases Working Party of the German Society for Haematology and Oncology," Haematologica, vol. 94, no. 1, pp. 113122, 2009.

[136] S. S. V. Henriet, P. E. Verweij, and A. Warris, “Aspergillus nidulans and chronic granulomatous disease: a unique host-pathogen interaction," The Journal of Infectious Diseases, vol. 206, no. 7, pp. 1128-1137, 2012.

[137] D. C. Vinh, A. F. Freeman, Y. R. Shea et al., "Mucormycosis in chronic granulomatous disease: association with iatrogenic immunosuppression," The Journal of Allergy and Clinical Immunology, vol. 123, no. 6, pp. 1411-1413, 2009.

[138] S. Henriet, P. E. Verweij, S. M. Holland, and A. Warris, "Invasive fungal infections in patients with chronic granulomatous disease," Advances in Experimental Medicine and Biology, vol. 764, pp. 27-55, 2013.

[139] C. C. Silliman, D. W. Lawellin, J. A. Lohr, B. M. Rodgers, and L. G. Donowitz, "Paecilomyces lilacinus infection in a child with chronic granulomatous disease," Journal of Infection, vol. 24, no. 2, pp. 191-195, 1992.

[140] P. R. Williamson, K. J. Kwon-Chung, and J. I. Gallin, "Successful treatment of Paecilomyces varioti infection in a patient with chronic granulomatous disease and a review of Paecilomyces species infections," Clinical Infectious Diseases, vol. 14, no. 5, pp. 1023-1026, 1992.

[141] S. S. De Ravin, M. Challipalli, V. Anderson et al., "Geosmithia argillacea: an emerging cause of invasive mycosis in human chronic granulomatous disease," Clinical Infectious Diseases, vol. 52, no. 6, pp. e136-e143, 2011.

[142] M. Machouart, D. Garcia-Hermoso, A. Rivier et al., "Emergence of disseminated infections due to Geosmithia argillacea in patients with chronic granulomatous disease receiving long-term azole antifungal prophylaxis," Journal of Clinical Microbiology, vol. 49, no. 4, pp. 1681-1683, 2011. 
[143] S. Giraud, L. Favennec, M. E. Bougnoux, and J. P. Bouchara, "Rasamsonia argillacea species complex: taxonomy, pathogenesis and clinical relevance," Future Microbiology, vol. 8, no. 8, pp. 967-978, 2013.

[144] P. E. Santos, E. Piontelli, Y. R. Shea et al., "Penicillium piceum infection: diagnosis and successful treatment in chronic granulomatous disease," Medical Mycology, vol. 44, no. 8, pp. 749-753, 2006.

[145] G. Haidar, C. S. Zerbe, M. Cheng, A. M. Zelazny, S. M. Holland, and K. R. Sheridan, "Phellinus species: an emerging cause of refractory fungal infections in patients with X-linked chronic granulomatous disease," Mycoses, vol. 60, no. 3, pp. 155-160, 2017.

[146] J. Dotis, Z. D. Pana, and E. Roilides, "Non-Aspergillus fungal infections in chronic granulomatous disease," Mycoses, vol. 56, no. 4, pp. 449-462, 2013.

[147] S. L. Newman, L. Gootee, and J. E. Gabay, "Human neutrophil-mediated fungistasis against Histoplasma capsulatum. Localization of fungistatic activity to the azurophil granules," The Journal of Clinical Investigation, vol. 92, no. 2, pp. 624-631, 1993.

[148] Y. Okura, N. Kawamura, M. Okano et al., "Fusarium falciforme infection in a patient with chronic granulomatous disease: unique long-term course of epidural abscess," Pediatrics International, vol. 57, no. 1, pp. e4-e6, 2015.

[149] B. Ozturk, L. Incesu, and I. Camlidag, "Chronic granulomatosis disease with meningitis and multiple brain abscesses," Pediatric Neurology, vol. 51, no. 4, pp. 589-590, 2014.

[150] G. Khotaei, A. Hirbod-Mobarakeh, D. Amirkashani, F. Manafi, and N. Rezaei, "Mycobacterium tuberculosis meningitis as the first presentation of chronic granulomatous disease," The Brazilian Journal of Infectious Diseases, vol. 16, no. 5, pp. 491-492, 2012.

[151] J. I. Gallin and E. S. Buescher, "Abnormal regulation of inflammatory skin responses in male patients with chronic granulomatous disease," Inflammation, vol. 7, no. 3, pp. 227-232, 1983.

[152] M. E. Ament and H. D. Ochs, "Gastrointestinal manifestations of chronic granulomatous disease," The New England Journal of Medicine, vol. 288, no. 8, pp. 382387, 1973.

[153] J. R. Sty, M. J. Chusid, D. P. Babbitt, and S. L. Werlin, "Involvement of the colon in chronic granulomatous disease of childhood," Radiology, vol. 132, no. 3, p. 618, 1979.

[154] N. T. Griscom, J. A. Kirkpatrick Jr., B. R. Girdany, W. E. Berdon, R. J. Grand, and G. G. Mackie, "Gastric antral narrowing in chronic granulomatous disease of childhood," Pediatrics, vol. 54, no. 4, pp. 456-460, 1974.

[155] J. W. Leiding, A. F. Freeman, B. E. Marciano et al., "Corticosteroid therapy for liver abscess in chronic granulomatous disease," Clinical Infectious Diseases, vol. 54, no. 5, pp. 694700, 2012.

[156] E. Venegas-Montoya, G. Sorcia-Ramirez, S. SchefflerMendoza et al., "Use of corticosteroids as an alternative to surgical treatment for liver abscesses in chronic granulomatous disease," Pediatric Blood \& Cancer, vol. 63, no. 12, pp. 2254-2255, 2016.

[157] J. J. Feld, N. Hussain, E. C. Wright et al., "Hepatic involvement and portal hypertension predict mortality in chronic granulomatous disease," Gastroenterology, vol. 134, no. 7, pp. 1917-1926, 2008.
[158] N. Hussain, J. J. Feld, D. E. Kleiner et al., "Hepatic abnormalities in patients with chronic granulomatous disease," Нераtology, vol. 45, no. 3, pp. 675-683, 2007.

[159] E. Gabrielli, A. W. Fothergill, L. Brescini et al., "Osteomyelitis caused by Aspergillus species: a review of 310 reported cases," Clinical Microbiology and Infection, vol. 20, no. 6, pp. 559565, 2014.

[160] M. L. Galluzzo, C. Hernandez, M. T. G. Davila et al., "Clinical and histopathological features and a unique spectrum of organisms significantly associated with chronic granulomatous disease osteomyelitis during childhood," Clinical Infectious Diseases, vol. 46, no. 5, pp. 745-749, 2008.

[161] M. C. M. Walther, H. Malech, A. Berman et al., "The urological manifestations of chronic granulomatous disease," The Journal of Urology, vol. 147, no. 5, pp. 1314-1318, 1992.

[162] N. Q. Agochukwu, A. R. Rastinehad, L. A. Richter et al., "Prostatic abscess in a pediatric patient with chronic granulomatous disease: report of a unique case and review of the literature," Journal of Pediatric Surgery, vol. 47, no. 2, pp. 400-403, 2012.

[163] A. Martini, I. Katafigiotis, S. Kalantzi et al., "Prostatic abscess in a patient with chronic granulomatous disease: a multidisciplinary intervention," Urologia, vol. 84, no. 4, pp. 267269, 2017.

[164] S. B. Kontras, J. G. Bodenbender, C. R. McClave, and J. P. Smith, "Interstitial cystitis in chronic granulomatous disease," The Journal of Urology, vol. 105, no. 4, pp. 575-578, 1971.

[165] D. Goldblatt, J. Butcher, A. J. Thrasher, and I. Russell-Eggitt, "Chorioretinal lesions in patients and carriers of chronic granulomatous disease," The Journal of Pediatrics, vol. 134, no. 6, pp. 780-783, 1999.

[166] Y. Wang, B. E. Marciano, D. Shen et al., "Molecular identification of bacterial DNA in the chorioretinal scars of chronic granulomatous disease," Journal of Clinical Immunology, vol. 33, no. 5, pp. 917-924, 2013.

[167] A. G. Palestine, S. M. Meyers, A. S. Fauci, and J. I. Gallin, "Ocular findings in patients with neutrophil dysfunction," American Journal of Ophthalmology, vol. 95, no. 5, pp. 598604, 1983.

[168] D. Isaacs, Y. M. Wright, D. G. Shaw, F. Raafat, and J. A. Walker-Smith, "Chronic granulomatous disease mimicking Crohn's disease," Journal of Pediatric Gastroenterology and Nutrition, vol. 4, no. 3, pp. 498-501, 1985.

[169] M. I. Spagnuolo, G. Russo, G. Giardino et al., "Chronic granulomatous disease with gastrointestinal presentation: diagnostic pitfalls and novel ultrastructural findings," Journal of Investigational Allergology \& Clinical Immunology, vol. 22, no. 7, pp. 527-529, 2012.

[170] R. A. Saul, "Gastric outlet obstruction in chronic granulomatous disease," The Journal of Pediatrics, vol. 114, no. 3, p. 505, 1989.

[171] G. Uzel, J. S. Orange, N. Poliak, B. E. Marciano, T. Heller, and S. M. Holland, "Complications of tumor necrosis factor- \pm blockade in chronic granulomatous disease-related colitis," Clinical Infectious Diseases, vol. 51, no. 12, pp. 1429-1434, 2010 .

[172] M. Pao, E. A. Wiggs, M. M. Anastacio et al., "Cognitive function in patients with chronic granulomatous disease: a preliminary report," Psychosomatics, vol. 45, no. 3, pp. 230234, 2004. 
[173] F. McKendrick, A. Cant, M. Pearce et al., "Cognitive ability in children with chronic granulomatous disease: a comparison of those managed conservatively with those who have undergone hematopoietic stem cell transplant," Neuropediatrics, vol. 44, no. 04, pp. 230-232, 2013.

[174] Z. Nayernia, V. Jaquet, and K. H. Krause, "New insights on NOX enzymes in the central nervous system," Antioxidants \& Redox Signaling, vol. 20, no. 17, pp. 2815-2837, 2014.

[175] M. T. Fischer, R. Sharma, J. L. Lim et al., "NADPH oxidase expression in active multiple sclerosis lesions in relation to oxidative tissue damage and mitochondrial injury," Brain, vol. 135, no. 3, pp. 886-899, 2012.

[176] D. C. Wu, D. B. Re, M. Nagai, H. Ischiropoulos, and S. Przedborski, "The inflammatory NADPH oxidase enzyme modulates motor neuron degeneration in amyotrophic lateral sclerosis mice," Proceedings of the National Academy of Sciences of the United States of America, vol. 103, no. 32, pp. 12132-12137, 2006.

[177] E. S. Buescher and J. I. Gallin, "Stature and weight in chronic granulomatous disease," The Journal of Pediatrics, vol. 104, no. 6, pp. 911-913, 1984.

[178] E. Soncini, M. A. Slatter, L. B. K. R. Jones et al., "Unrelated donor and HLA-identical sibling haematopoietic stem cell transplantation cure chronic granulomatous disease with good long-term outcome and growth," British Journal of Haematology, vol. 145, no. 1, pp. 73-83, 2009.

[179] M. Heltzer, A. F. Jawad, J. Rae, J. T. Curnutte, and K. E. Sullivan, "Diminished T cell numbers in patients with chronic granulomatous disease," Clinical Immunology, vol. 105, no. 3, pp. 273-278, 2002.

[180] E. G. Carnide, C. A. Jacob, A. M. Castro, and A. C. Pastorino, "Clinical and laboratory aspects of chronic granulomatous disease in description of eighteen patients," Pediatric Allergy and Immunology, vol. 16, no. 1, pp. 5-9, 2005.

[181] C. E. Watkins, J. Litchfield, E. Song et al., "Chronic granulomatous disease, the McLeod phenotype and the contiguous gene deletion syndrome-a review," Clinical and Molecular Allergy, vol. 9, no. 1, p. 13, 2011.

[182] J. Peng, C. M. Redman, X. Wu et al., "Insights into extensive deletions around the XK locus associated with McLeod phenotype and characterization of two novel cases," Gene, vol. 392, no. 1-2, pp. 142-150, 2007.

[183] E. R. Giblett, S. J. Klebanoff, S. H. Pincus, J. Swanson, B. H. Park, and J. Mccullough, "Kell phenotypes in chronic granulomatous disease: a potential transfusion hazard," The Lancet, vol. 297, no. 7711, pp. 1235-1236, 1971.

[184] M. A. Deardorff, H. Gaddipati, P. Kaplan et al., "Complex management of a patient with a contiguous Xp11.4 gene deletion involving ornithine transcarbamylase: a role for detailed molecular analysis in complex presentations of classical diseases," Molecular Genetics and Metabolism, vol. 94, no. 4, pp. 498-502, 2008.

[185] M. J. Stasia, M. Mollin, C. Martel et al., "Functional and genetic characterization of two extremely rare cases of Williams-Beuren syndrome associated with chronic granulomatous disease," European Journal of Human Genetics, vol. 21, no. 10, pp. 1079-1084, 2013.

[186] E. Gilbert-Barness, T. Fox, G. Morrow, M. Luquette, and H. H. Pomerance, "Williams syndrome associated with Crohn disease, multiple infections, and chronic granulomatous disease," Fetal and Pediatric Pathology, vol. 23, no. 1, pp. 29-37, 2004.
[187] K. A. Gelderman, M. Hultqvist, A. Pizzolla et al., "Macrophages suppress $\mathrm{T}$ cell responses and arthritis development in mice by producing reactive oxygen species," The Journal of Clinical Investigation, vol. 117, no. 10, pp. 3020-3028, 2007.

[188] P. Olofsson, J. Holmberg, J. Tordsson, S. Lu, B. Akerstrom, and R. Holmdahl, "Positional identification of Ncf1 as a gene that regulates arthritis severity in rats," Nature Genetics, vol. 33, no. 1, pp. 25-32, 2003.

[189] A. George-Chandy, I. Nordström, E. Nygren et al., “Th17 development and autoimmune arthritis in the absence of reactive oxygen species," European Journal of Immunology, vol. 38, no. 4, pp. 1118-1126, 2008.

[190] Z. Wen, Y. Shimojima, T. Shirai et al., "NADPH oxidase deficiency underlies dysfunction of aged $\mathrm{CD}^{+}$Tregs," The Journal of Clinical Investigation, vol. 126, no. 5, pp. 19531967, 2016.

[191] C. B. Foster, T. Lehrnbecher, F. Mol et al., "Host defense molecule polymorphisms influence the risk for immunemediated complications in chronic granulomatous disease," The Journal of Clinical Investigation, vol. 102, no. 12, pp. 2146-2155, 1998.

[192] S. S. De Ravin, N. Naumann, E. W. Cowen et al., "Chronic granulomatous disease as a risk factor for autoimmune disease," The Journal of Allergy and Clinical Immunology, vol. 122, no. 6, pp. 1097-1103, 2008.

[193] F. Fattahi, M. Badalzadeh, L. Sedighipour et al., "Inheritance pattern and clinical aspects of 93 Iranian patients with chronic granulomatous disease," Journal of Clinical Immunology, vol. 31, no. 5, pp. 792-801, 2011.

[194] B. S. Shamsian, D. Mansouri, Z. Pourpak et al., "Autosomal recessive chronic granulomatous disease, IgA deficiency and refractory autoimmune thrombocytopenia responding to anti-CD20 monoclonal antibody," Iranian Journal of Allergy, Asthma, and Immunology, vol. 7, no. 3, pp. 181184, 2008.

[195] J. Trelinski, K. Chojnowski, M. Kurenko-Deptuch, M. Kasznicki, E. Bernatowska, and T. Robak, "Successful treatment of refractory autoimmune thrombocytopenia with rituximab and cyclosporin $\mathrm{A}$ in a patient with chronic granulomatous disease," Annals of Hematology, vol. 84, no. 12, pp. 835-836, 2005.

[196] B. W. Lee and H. K. Yap, "Polyarthritis resembling juvenile rheumatoid arthritis in a girl with chronic granulomatous disease," Arthritis \& Rheumatism, vol. 37, no. 5, pp. 773776, 1994.

[197] C. O. Jacob, M. Eisenstein, M. C. Dinauer et al., "Lupus-associated causal mutation in neutrophil cytosolic factor 2 (NCF2) brings unique insights to the structure and function of NADPH oxidase," Proceedings of the National Academy of Sciences of the United States of America, vol. 109, no. 2, pp. E59-E67, 2012.

[198] L. M. Olsson, A.-K. Lindqvist, H. Källberg et al., “A casecontrol study of rheumatoid arthritis identifies an associated single nucleotide polymorphism in the NCF4 gene, supporting a role for the NADPH-oxidase complex in autoimmunity," Arthritis Research \& Therapy, vol. 9, no. 5, article R98, 2007.

[199] J. D. Rioux, R. J. Xavier, K. D. Taylor et al., "Genome-wide association study identifies new susceptibility loci for Crohn disease and implicates autophagy in disease pathogenesis," Nature Genetics, vol. 39, no. 5, pp. 596-604, 2007. 
[200] R. L. Roberts, J. E. Hollis-Moffatt, R. B. Gearry, M. A. Kennedy, M. L. Barclay, and T. R. Merriman, "Confirmation of association of IRGM and NCF4 with ileal Crohn's disease in a population-based cohort," Genes \& Immunity, vol. 9, no. 6, pp. 561-565, 2008.

[201] J. W. Leiding, B. E. Marciano, C. S. Zerbe, S. S. DeRavin, H. L. Malech, and S. M. Holland, "Diabetes, renal and cardiovascular disease in $47^{\text {phox-1- }}$ chronic granulomatous disease," Journal of Clinical Immunology, vol. 33, no. 4, pp. 725-730, 2013.

[202] A. M. Muise, T. Walters, W. Xu et al., "Single nucleotide polymorphisms that increase expression of the guanosine triphosphatase RAC1 are associated with ulcerative colitis," Gastroenterology, vol. 141, no. 2, pp. 633-641, 2011.

[203] A. M. Muise, S. B. Snapper, and S. Kugathasan, "The age of gene discovery in very early onset inflammatory bowel disease," Gastroenterology, vol. 143, no. 2, pp. 285-288, 2012.

[204] S. S. Dhillon, R. Fattouh, A. Elkadri et al., "Variants in nicotinamide adenine dinucleotide phosphate oxidase complex components determine susceptibility to very early onset inflammatory bowel disease," Gastroenterology, vol. 147, no. 3, pp. 680-689.e2, 2014.

[205] P. Hayes, S. Dhillon, K. O’Neill et al., "Defects in nicotinamide-adenine dinucleotide phosphate oxidase genes NOX1 and DUOX2 in very early onset inflammatory bowel disease," Cellular and Molecular Gastroenterology and Hepatology, vol. 1, no. 5, pp. 489-502, 2015.

[206] M. Anderson-Cohen, S. M. Holland, D. B. Kuhns et al., "Severe phenotype of chronic granulomatous disease presenting in a female with a de novo mutation in gp91-phox and a non familial, extremely skewed $\mathrm{X}$ chromosome inactivation," Clinical Immunology, vol. 109, no. 3, pp. 308-317, 2003.

[207] B. Wolach, Y. Scharf, R. Gavrieli, M. de Boer, and D. Roos, "Unusual late presentation of X-linked chronic granulomatous disease in an adult female with a somatic mosaic for a novel mutation in CYBB," Blood, vol. 105, no. 1, pp. 61-66, 2005.

[208] J. Roesler, "Carriers of X-linked chronic granulomatous disease at risk," Clinical Immunology, vol. 130, no. 2, p. 233, 2009.

[209] B. E. Marciano, C. S. Zerbe, E. Liana Falcone et al., "X-linked carriers of chronic granulomatous disease: illness, lyonization, and stability," The Journal of Allergy and Clinical Immunology, 2017.

[210] J. Hafner, A. Enderlin, R. A. Seger et al., "Discoid lupus erythematosus-like lesions in carriers of X-linked chronic granulomatous disease," The British Journal of Dermatology, vol. 127, no. 4, pp. 446-447, 1992.

[211] C. M. Cale, L. Morton, and D. Goldblatt, "Cutaneous and other lupus-like symptoms in carriers of X-linked chronic granulomatous disease: incidence and autoimmune serology," Clinical \& Experimental Immunology, vol. 148, no. 1, pp. 79-84, 2007.

[212] C. Xie, T. Cole, C. McLean, and J. C. Su, “Association between discoid lupus erythematosus and chronic granulomatous disease-report of two cases and review of the literature," Pediatric Dermatology, vol. 33, no. 2, pp. e114-e120, 2016.

[213] F. Hauck, S. Koletzko, C. Walz et al., "Diagnostic and treatment options for severe IBD in female X-CGD carriers with non-random X-inactivation," Journal of Crohn's \& Colitis, vol. 10, no. 1, pp. 112-115, 2016.
[214] A. C. Battersby, C. M. Cale, D. Goldblatt, and A. R. Gennery, "Clinical manifestations of disease in X-linked carriers of chronic granulomatous disease," Journal of Clinical Immunology, vol. 33, no. 8, pp. 1276-1284, 2013.

[215] S. Alers, A. S. Loffler, S. Wesselborg, and B. Stork, "Role of AMPK-mTOR-Ulk1/2 in the regulation of autophagy: cross talk, shortcuts, and feedbacks," Molecular and Cellular Biology, vol. 32, no. 1, pp. 2-11, 2012.

[216] R. D'Assante, A. Fusco, L. Palamaro et al., "Abnormal cell-clearance and accumulation of autophagic vesicles in lymphocytes from patients affected with AtaxiaTeleangiectasia," Clinical Immunology, vol. 175, pp. 1625, 2017.

[217] V. Deretic, "Autophagy in immunity and cell-autonomous defense against intracellular microbes," Immunological Reviews, vol. 240, no. 1, pp. 92-104, 2011.

[218] B. Levine, N. Mizushima, and H. W. Virgin, "Autophagy in immunity and inflammation,” Nature, vol. 469, no. 7330, pp. 323-335, 2011.

[219] S. Al-Khodor, K. Marshall-Batty, V. Nair, L. Ding, D. E. Greenberg, and I. D. C. Fraser, "Burkholderia cenocepacia J2315 escapes to the cytosol and actively subverts autophagy in human macrophages," Cellular Microbiology, vol. 16, no. 3, pp. 378-395, 2014.

[220] I. Kyrmizi, M. S. Gresnigt, T. Akoumianaki et al., "Corticosteroids block autophagy protein recruitment in Aspergillus fumigatus phagosomes via targeting dectin-1/Syk kinase signaling," The Journal of Immunology, vol. 191, no. 3, pp. 1287-1299, 2013.

[221] E. K. Jo, J. M. Yuk, D. M. Shin, and C. Sasakawa, "Roles of autophagy in elimination of intracellular bacterial pathogens," Frontiers in Immunology, vol. 4, p. 97, 2013.

[222] J. Huang and J. H. Brumell, "Bacteria-autophagy interplay: a battle for survival," Nature Reviews Microbiology, vol. 12, no. 2, pp. 101-114, 2014.

[223] M. A. Sanjuan, C. P. Dillon, S. W. G. Tait et al., "Toll-like receptor signalling in macrophages links the autophagy pathway to phagocytosis," Nature, vol. 450, no. 7173, pp. 1253-1257, 2007.

[224] J. Huang, V. Canadien, G. Y. Lam et al., "Activation of antibacterial autophagy by NADPH oxidases," Proceedings of the National Academy of Sciences of the United States of America, vol. 106, no. 15, pp. 6226-6231, 2009.

[225] R. Scherz-Shouval, E. Shvets, E. Fass, H. Shorer, L. Gil, and Z. Elazar, "Reactive oxygen species are essential for autophagy and specifically regulate the activity of Atg4," The EMBO Journal, vol. 26, no. 7, pp. 1749-1760, 2007.

[226] C. Schürmann, F. Rezende, C. Kruse et al., "The NADPH oxidase Nox4 has anti-atherosclerotic functions," European Heart Journal, vol. 36, no. 48, pp. 3447-3456, 2015.

[227] P. K. Witting, B. S. Rayner, B. J. Wu, N. A. Ellis, and R. Stocker, "Hydrogen peroxide promotes endothelial dysfunction by stimulating multiple sources of superoxide anion radical production and decreasing nitric oxide bioavailability," Cellular Physiology and Biochemistry, vol. 20, no. 5, pp. 255-268, 2007.

[228] T. Cascino, G. Csanyi, I. Al Ghouleh et al., "Adventitiaderived hydrogen peroxide impairs relaxation of the rat carotid artery via smooth muscle cell p38 mitogen-activated protein kinase," Antioxidants \& Redox Signaling, vol. 15, no. 6, pp. 1507-1515, 2011. 
[229] P. Wenzel, S. Kossmann, T. Munzel, and A. Daiber, "Redox regulation of cardiovascular inflammation - immunomodulatory function of mitochondrial and Nox-derived reactive oxygen and nitrogen species," Free Radical Biology \& Medicine, vol. 109, pp. 48-60, 2017.

[230] D. W. Infanger, R. V. Sharma, and R. L. Davisson, "NADPH oxidases of the brain: distribution, regulation, and function," Antioxidants \& Redox Signaling, vol. 8, no. 9-10, pp. 15831596, 2006.

[231] T. M. Paravicini and R. M. Touyz, "NADPH oxidases, reactive oxygen species, and hypertension: clinical implications and therapeutic possibilities," Diabetes Care, vol. 31, Supplement 2, pp. S170-S180, 2008.

[232] M. Kawano, K. Miyamoto, Y. Kaito, H. Sumimoto, and M. Tamura, "Noxa1 as a moderate activator of Nox2-based NADPH oxidase," Archives of Biochemistry and Biophysics, vol. 519, no. 1, pp. 1-7, 2012.

[233] M. Ushio-Fukai, A. M. Zafari, T. Fukui, N. Ishizaka, and K. K. Griendling, "p $22^{\text {phox }}$ is a critical component of the superoxide-generating NADH/NADPH oxidase system and regulates angiotensin iiinduced hypertrophy in vascular smooth muscle cells," Journal of Biological Chemistry, vol. 271, no. 38, pp. 23317-23321, 1996.

[234] D. Sorescu, D. Weiss, B. Lassègue et al., "Superoxide production and expression of Nox family proteins in human atherosclerosis," Circulation, vol. 105, no. 12, pp. 14291435, 2002.

[235] I. M. Quesada, A. Lucero, C. Amaya et al., "Selective inactivation of NADPH oxidase 2 causes regression of vascularization and the size and stability of atherosclerotic plaques," Atherosclerosis, vol. 242, no. 2, pp. 469-475, 2015.

[236] P. A. Barry-Lane, C. Patterson, M. van der Merwe et al., "p47phox is required for atherosclerotic lesion progression in $A p o E^{-/-}$mice," The Journal of Clinical Investigation, vol. 108, no. 10, pp. 1513-1522, 2001.

[237] K. Szöcs, B. Lassègue, D. Sorescu et al., "Upregulation of Noxbased NAD $(\mathrm{P}) \mathrm{H}$ oxidases in restenosis after carotid injury," Arteriosclerosis, Thrombosis, and Vascular Biology, vol. 22, no. 1, pp. 21-27, 2002.

[238] G. M. Jacobson, H. M. Dourron, J. Liu et al., "Novel $\mathrm{NAD}(\mathrm{P}) \mathrm{H}$ oxidase inhibitor suppresses angioplasty-induced superoxide and neointimal hyperplasia of rat carotid artery," Circulation Research, vol. 92, no. 6, pp. 637-643, 2003.

[239] M. Weaver, J. Liu, D. Pimentel et al., "Adventitial delivery of dominant-negative $\mathrm{p} 67^{\text {phox }}$ attenuates neointimal hyperplasia of the rat carotid artery," American Journal of Physiology Heart and Circulatory Physiology, vol. 290, no. 5, pp. H1933-H1941, 2006.

[240] J. Feng, S. M. Damrauer, M. Lee, F. W. Sellke, C. Ferran, and M. R. Abid, "Endothelium-dependent coronary vasodilatation requires NADPH oxidase-derived reactive oxygen species," Arteriosclerosis, Thrombosis, and Vascular Biology, vol. 30, no. 9, pp. 1703-1710, 2010.

[241] X. Lu, C. Q. Dang, X. Guo et al., "Elevated oxidative stress and endothelial dysfunction in right coronary artery of right ventricular hypertrophy," Journal of Applied Physiology, vol. 110, no. 6, pp. 1674-1681, 2011.

[242] J. J. Khatri, C. Johnson, R. Magid et al., "Vascular oxidant stress enhances progression and angiogenesis of experimental atheroma," Circulation, vol. 109, no. 4, pp. 520-525, 2004.
[243] H. Azumi, N. Inoue, S. Takeshita et al., "Expression of NADH/NADPH oxidase $\mathrm{p} 22^{\text {phox }}$ in human coronary arteries," Circulation, vol. 100, no. 14, pp. 1494-1498, 1999.

[244] T. J. Guzik, J. Sadowski, B. Guzik et al., "Coronary artery superoxide production and Nox isoform expression in human coronary artery disease," Arteriosclerosis, Thrombosis, and Vascular Biology, vol. 26, no. 2, pp. 333-339, 2006.

[245] D. I. Brown and K. K. Griendling, "Nox proteins in signal transduction," Free Radical Biology \& Medicine, vol. 47, no. 9, pp. 1239-1253, 2009.

[246] A. Konior, A. Schramm, M. Czesnikiewicz-Guzik, and T. J. Guzik, "NADPH oxidases in vascular pathology," Antioxidants \& Redox Signaling, vol. 20, no. 17, pp. 2794-2814, 2014.

[247] F. Violi, P. Pignatelli, C. Pignata et al., "Reduced atherosclerotic burden in subjects with genetically determined low oxidative stress," Arteriosclerosis, Thrombosis, and Vascular Biology, vol. 33, no. 2, pp. 406-412, 2013.

[248] K. Matsuno, H. Yamada, K. Iwata et al., "Nox1 is involved in angiotensin II-mediated hypertension: a study in Nox1deficient mice," Circulation, vol. 112, no. 17, pp. 2677-2685, 2005.

[249] M. K. Cathcart, "Regulation of superoxide anion production by NADPH oxidase in monocytes/macrophages: contributions to atherosclerosis," Arteriosclerosis, Thrombosis, and Vascular Biology, vol. 24, no. 1, pp. 23-28, 2004.

[250] R. Carnevale, S. Sciarretta, F. Violi et al., "Acute impact of tobacco vs electronic cigarette smoking on oxidative stress and vascular function," Chest, vol. 150, no. 3, pp. 606-612, 2016.

[251] L. Loffredo, R. Carnevale, L. Perri et al., "NOX2-mediated arterial dysfunction in smokers: acute effect of dark chocolate," Heart, vol. 97, no. 21, pp. 1776-1781, 2011.

[252] L. Loffredo, R. Carnevale, R. Cangemi et al., "NOX2 upregulation is associated with artery dysfunction in patients with peripheral artery disease," International Journal of Cardiology, vol. 165, no. 1, pp. 184-192, 2013.

[253] M. Del Ben, M. Fabiani, L. Loffredo et al., "Oxidative stress mediated arterial dysfunction in patients with obstructive sleep apnoea and the effect of continuous positive airway pressure treatment," BMC Pulmonary Medicine, vol. 12, p. 36, 2012.

[254] L. Loffredo, F. Martino, R. Carnevale et al., "Obesity and hypercholesterolemia are associated with NOX2 generated oxidative stress and arterial dysfunction," The Journal of Pediatrics, vol. 161, no. 6, pp. 1004-1009, 2012.

[255] F. Martino, L. Loffredo, R. Carnevale et al., "Oxidative stress is associated with arterial dysfunction and enhanced intimamedia thickness in children with hypercholesterolemia: the potential role of nicotinamide-adenine dinucleotide phosphate oxidase," Pediatrics, vol. 122, no. 3, pp. e648-e655, 2008.

[256] L. Loffredo, A. M. Zicari, F. Occasi et al., "Endothelial dysfunction and oxidative stress in children with sleep disordered breathing: role of NADPH oxidase," Atherosclerosis, vol. 240, no. 1, pp. 222-227, 2015.

[257] G. B. Mancini, B. Dahlof, and J. Diez, "Surrogate markers for cardiovascular disease: structural markers," Circulation, vol. 109, no. 25, Supplement 1, pp. IV-22-IV-30, 2004.

[258] C. T. Sibley, T. Estwick, A. Zavodni et al., "Assessment of atherosclerosis in chronic granulomatous disease," Circulation, vol. 130, no. 23, pp. 2031-2039, 2014. 
[259] T. J. Guzik, J. Sadowski, B. Kapelak et al., "Systemic regulation of vascular $\mathrm{NAD}(\mathrm{P}) \mathrm{H}$ oxidase activity and Nox isoform expression in human arteries and veins," Arteriosclerosis, Thrombosis, and Vascular Biology, vol. 24, no. 9, pp. 16141620, 2004.

[260] N. West, T. Guzik, E. Black, and K. Channon, "Enhanced superoxide production in experimental venous bypass graft intimal hyperplasia: role of NAD(P)H oxidase," Arteriosclerosis, Thrombosis, and Vascular Biology, vol. 21, no. 2, pp. 189-194, 2001.

[261] T. J. Guzik, W. Chen, M. C. Gongora et al., "Calciumdependent NOX5 nicotinamide adenine dinucleotide phosphate oxidase contributes to vascular oxidative stress in human coronary artery disease," Journal of the American College of Cardiology, vol. 52, no. 22, pp. 1803-1809, 2008.

[262] P. J. Pagano, S. J. Chanock, D. A. Siwik, W. S. Colucci, and J. K. Clark, “Angiotensin II induces p67 ${ }^{\text {phox }}$ mRNA expression and NADPH oxidase superoxide generation in rabbit aortic adventitial fibroblasts," Hypertension, vol. 32, no. 2, pp. 331-337, 1998.

[263] U. Landmesser, H. Cai, S. Dikalov et al., "Role of $p 47^{\text {phox }}$ in vascular oxidative stress and hypertension caused by angiotensin II," Hypertension, vol. 40, no. 4, pp. 511-515, 2002.

[264] K. Grote, M. Ortmann, G. Salguero et al., "Critical role for $\mathrm{p} 47^{\text {phox }}$ in renin-angiotensin system activation and blood pressure regulation," Cardiovascular Research, vol. 71, no. 3, pp. 596-605, 2006.

[265] J. M. Li, S. Wheatcroft, L. M. Fan, M. T. Kearney, and A. M. Shah, "Opposing roles of $\mathrm{p} 47^{\text {phox }}$ in basal versus angiotensin II-stimulated alterations in vascular $\mathrm{O}_{2}^{-}$production, vascular tone, and mitogen-activated protein kinase activation," Circulation, vol. 109, no. 10, pp. 1307-1313, 2004.

[266] M. Thomas, D. Gavrila, M. L. McCormick et al., "Deletion of $\mathrm{p} 47^{\text {phox }}$ attenuates angiotensin II-induced abdominal aortic aneurysm formation in apolipoprotein E-deficient mice," Circulation, vol. 114, no. 5, pp. 404-413, 2006.

[267] J. Y. Youn, L. Gao, and H. Cai, “The p47 $7^{\text {phox }}$ - and NADPH oxidase organiser 1 (NOXO1)-dependent activation of NADPH oxidase 1 (NOX1) mediates endothelial nitric oxide synthase (eNOS) uncoupling and endothelial dysfunction in a streptozotocin-induced murine model of diabetes," Diabetologia, vol. 55, no. 7, pp. 2069-2079, 2012.

[268] T. Aoki, M. Nishimura, H. Kataoka, R. Ishibashi, K. Nozaki, and N. Hashimoto, "Reactive oxygen species modulate growth of cerebral aneurysms: a study using the free radical scavenger edaravone and $\mathrm{p}^{\mathrm{phox}-1-}$ mice," Laboratory Investigation, vol. 89, no. 7, pp. 730-741, 2009.

[269] A. Dikalova, R. Clempus, B. Lassègue et al., "Nox1 overexpression potentiates angiotensin II-induced hypertension and vascular smooth muscle hypertrophy in transgenic mice," Circulation, vol. 112, no. 17, pp. 2668-2676, 2005.

[270] K. Laude, H. Cai, B. Fink et al., "Hemodynamic and biochemical adaptations to vascular smooth muscle overexpression of p22 phox in mice," American Journal of Physiology Heart and Circulatory Physiology, vol. 288, no. 1, pp. H7H12, 2005.

[271] D. S. Weber, P. Rocic, A. M. Mellis et al., "Angiotensin IIinduced hypertrophy is potentiated in mice overexpressing p $22^{\text {phox }}$ in vascular smooth muscle," American Journal of Physiology - Heart and Circulatory Physiology, vol. 288, no. 1, pp. H37-H42, 2005.
[272] G. Gavazzi, B. Banfi, C. Deffert et al., "Decreased blood pressure in NOX1-deficient mice," FEBS Letters, vol. 580, no. 2, pp. 497-504, 2006.

[273] G. Gavazzi, C. Deffert, C. Trocme, M. Schappi, F. R. Herrmann, and K. H. Krause, "NOX1 deficiency protects from aortic dissection in response to angiotensin II," Hypertension, vol. 50, no. 1, pp. 189-196, 2007.

[274] P. Modlinger, T. Chabrashvili, P. S. Gill et al., "RNA silencing in vivo reveals role of $\mathrm{p} 22^{\mathrm{phox}}$ in rat angiotensin slow pressor response," Hypertension, vol. 47, no. 2, pp. 238-244, 2006.

[275] H. D. Wang, S. Xu, D. G. Johns et al., "Role of NADPH oxidase in the vascular hypertrophic and oxidative stress response to angiotensin II in mice," Circulation Research, vol. 88, no. 9, pp. 947-953, 2001.

[276] O. Jung, J. G. Schreiber, H. Geiger, T. Pedrazzini, R. Busse, and R. P. Brandes, "gp91phox-containing NADPH oxidase mediates endothelial dysfunction in renovascular hypertension," Circulation, vol. 109, no. 14, pp. 1795-1801, 2004.

[277] R. Ray, C. E. Murdoch, M. Wang et al., "Endothelial Nox4 NADPH oxidase enhances vasodilatation and reduces blood pressure in vivo," Arteriosclerosis, Thrombosis, and Vascular Biology, vol. 31, no. 6, pp. 1368-1376, 2011.

[278] K. Schroder, M. Zhang, S. Benkhoff et al., "Nox4 is a protective reactive oxygen species generating vascular NADPH oxidase," Circulation Research, vol. 110, no. 9, pp. 1217-1225, 2012.

[279] C. Kleinschnitz, H. Grund, K. Wingler et al., "Post-stroke inhibition of induced NADPH oxidase type 4 prevents oxidative stress and neurodegeneration," PLoS Biology, vol. 8, no. 9, p. e1000479, 2010.

[280] C. F. Liang, J. T. Liu, Y. Wang, A. Xu, and P. M. Vanhoutte, "Toll-like receptor 4 mutation protects obese mice against endothelial dysfunction by decreasing NADPH oxidase isoforms 1 and 4," Arteriosclerosis, Thrombosis, and Vascular Biology, vol. 33, no. 4, pp. 777-784, 2013.

[281] T. J. Guzik, N. E. J. West, E. Black et al., "Vascular superoxide production by $\mathrm{NAD}(\mathrm{P}) \mathrm{H}$ oxidase: association with endothelial dysfunction and clinical risk factors," Circulation Research, vol. 86, no. 9, pp. e85-e90, 2000.

[282] Q. Li, G. B. Fu, J. T. Zheng et al., "NADPH oxidase subunit p $22^{\text {phox }}$-mediated reactive oxygen species contribute to angiogenesis and tumor growth through AKT and ERK1/2 signaling pathways in prostate cancer," Biochimica et Biophysica Acta (BBA) - Molecular Cell Research, vol. 1833, no. 12, pp. 3375-3385, 2013.

[283] M. Ushio-Fukai and N. Urao, "Novel role of NADPH oxidase in angiogenesis and stem/progenitor cell function," Antioxidants \& Redox Signaling, vol. 11, no. 10, pp. 25172533, 2009.

[284] B. Govindarajan, J. E. Sligh, B. J. Vincent et al., "Overexpression of Akt converts radial growth melanoma to vertical growth melanoma," The Journal of Clinical Investigation, vol. 117, no. 3, pp. 719-729, 2007.

[285] I. Diebold, A. Petry, J. Hess, and A. Gorlach, "The NADPH oxidase subunit NOX4 is a new target gene of the hypoxiainducible factor-1," Molecular Biology of the Cell, vol. 21, no. 12, pp. 2087-2096, 2010.

[286] A. M. Evangelista, M. D. Thompson, V. M. Bolotina, X. Y. Tong, and R. A. Cohen, "Nox4- and Nox2-dependent oxidant production is required for VEGF-induced SERCA 
cysteine-674 S-glutathiolation and endothelial cell migration," Free Radical Biology \& Medicine, vol. 53, no. 12, pp. 2327-2334, 2012.

[287] Y. M. Kim, S. J. Kim, R. Tatsunami, H. Yamamura, T. Fukai, and M. Ushio-Fukai, "ROS-induced ROS release orchestrated by Nox4, Nox2, and mitochondria in VEGF signaling and angiogenesis," American Journal of Physiology - Cell Physiology, vol. 312, no. 6, pp. C749-C764, 2017.

[288] N. Sadaghianloo, K. Yamamoto, H. Bai et al., "Increased oxidative stress and hypoxia inducible factor-1 expression during arteriovenous fistula maturation," Annals of Vascular Surgery, vol. 41, pp. 225-234, 2017.

[289] J. L. Arbiser, J. Petros, R. Klafter et al., "Reactive oxygen generated by Nox1 triggers the angiogenic switch," Proceedings of the National Academy of Sciences of the United States of America, vol. 99, no. 2, pp. 715-720, 2002.

[290] S. Garrido-Urbani, S. Jemelin, C. Deffert et al., "Targeting vascular NADPH oxidase 1 blocks tumor angiogenesis through a PPAR $\alpha$ mediated mechanism," PLoS One, vol. 6, no. 2, article e14665, 2011.

[291] C. D. Fike, J. C. Slaughter, M. R. Kaplowitz, Y. Zhang, and J. L. Aschner, "Reactive oxygen species from NADPH oxidase contribute to altered pulmonary vascular responses in piglets with chronic hypoxia-induced pulmonary hypertension," American Journal of Physiology - Lung Cellular and Molecular Physiology, vol. 295, no. 5, pp. L881-L888, 2008.

[292] M. Mittal, M. Roth, P. Konig et al., "Hypoxia-dependent regulation of nonphagocytic NADPH oxidase subunit NOX4 in the pulmonary vasculature," Circulation Research, vol. 101, no. 3, pp. 258-267, 2007.

[293] K. D. O'Brien, C. E. Alpers, J. E. Hokanson, S. Wang, and A. Chait, "Oxidation-specific epitopes in human coronary atherosclerosis are not limited to oxidized low-density lipoprotein," Circulation, vol. 94, no. 6, pp. 1216-1225, 1996.

[294] E. Galkina, A. Kadl, J. Sanders, D. Varughese, I. J. Sarembock, and K. Ley, "Lymphocyte recruitment into the aortic wall before and during development of atherosclerosis is partially L-selectin dependent," The Journal of Experimental Medicine, vol. 203, no. 5, pp. 1273-1282, 2006.

[295] A. Kadl, E. Galkina, and N. Leitinger, "Induction of CCR2dependent macrophage accumulation by oxidized phospholipids in the air-pouch model of inflammation," Arthritis \& Rheumatism, vol. 60, no. 5, pp. 1362-1371, 2009.

[296] E. K. Koltsova, Z. Garcia, G. Chodaczek et al., "Dynamic T cell-APC interactions sustain chronic inflammation in atherosclerosis," The Journal of Clinical Investigation, vol. 122, no. 9, pp. 3114-3126, 2012.

[297] A. Vinh, W. Chen, Y. Blinder et al., "Inhibition and genetic ablation of the B7/CD28 T-cell costimulation axis prevents experimental hypertension," Circulation, vol. 122, no. 24, pp. 2529-2537, 2010.

[298] C. A. Martinez, S. Shah, W. T. Shearer et al., "Excellent survival after sibling or unrelated donor stem cell transplantation for chronic granulomatous disease," The Journal of Allergy and Clinical Immunology, vol. 129, no. 1, pp. 176$183,2012$.

[299] A. R. Gennery, M. A. Slatter, L. Grandin et al., "Transplantation of hematopoietic stem cells and long-term survival for primary immunodeficiencies in Europe: entering a new century, do we do better?," The Journal of Allergy and Clinical Immunology, vol. 126, no. 3, pp. 602-610.e11, 2010.
[300] T. Güngör, P. Teira, M. Slatter et al., "Reduced-intensity conditioning and HLA-matched haemopoietic stem-cell transplantation in patients with chronic granulomatous disease: a prospective multicentre study," The Lancet, vol. 383, no. 9915, pp. 436-448, 2014.

[301] B. Morillo-Gutierrez, R. Beier, K. Rao et al., "Treosulfanbased conditioning for allogeneic HSCT in children with chronic granulomatous disease: a multicenter experience," Blood, vol. 128, no. 3, pp. 440-448, 2016.

[302] A. Ahlin, J. Fugelang, M. de Boer, O. Ringden, A. Fasth, and J. Winiarski, "Chronic granulomatous disease - haematopoietic stem cell transplantation versus conventional treatment," Acta Paediatrica, vol. 102, no. 11, pp. 10871094, 2013.

[303] J. W. Leiding and S. M. Holland, "Chronic granulomatous disease," in GeneReviews ${ }^{\circledR}$, M. P. Adam, H. H. Ardinger, R. A. Pagon, S. E. Wallace, B. LJH, H. C. Mefford, K. Stephens, A. Amemiya and N. Ledbetter, Eds., University of Washington, Seattle, Seattle, WA, USA, 1993.

[304] M. Migliavacca, A. Assanelli, F. Ferrua et al., "Pioglitazone as a novel therapeutic approach in chronic granulomatous disease," The Journal of Allergy and Clinical Immunology, vol. 137, no. 6, pp. 2016-1915.e2, 2016.

[305] R. F. Fernandez-Boyanapalli, S. Courtney Frasch, S. M. Thomas et al., "Pioglitazone restores phagocyte mitochondrial oxidants and bactericidal capacity in chronic granulomatous disease," The Journal of Allergy and Clinical Immunology, vol. 135, no. 2, pp. 517-527.e12, 2015.

[306] A. Aiuti, R. Bacchetta, R. Seger, A. Villa, and M. CavazzanaCalvo, "Gene therapy for primary immunodeficiencies: part 2," Current Opinion in Immunology, vol. 24, no. 5, pp. 585-591, 2012.

[307] D. Goldblatt, "Recent advances in chronic granulomatous disease," Journal of Infection, vol. 69, Supplement 1, pp. S32-S35, 2014.

[308] S. Sekhsaria, T. A. Fleisher, S. Vowells et al., "Granulocyte colony-stimulating factor recruitment of $\mathrm{CD} 34+$ progenitors to peripheral blood: impaired mobilization in chronic granulomatous disease and adenosine deaminase-deficient severe combined immunodeficiency disease patients," Blood, vol. 88, no. 3, pp. 1104-1112, 1996.

[309] W. S. Goebel and M. C. Dinauer, "Gene therapy for chronic granulomatous disease," Acta Haematologica, vol. 110, no. 23, pp. 86-92, 2003.

[310] M. P. Cicalese and A. Aiuti, "Clinical applications of gene therapy for primary immunodeficiencies," Human Gene Therapy, vol. 26, no. 4, pp. 210-219, 2015.

[311] M. Grez, J. Reichenbach, J. Schwable, R. Seger, M. C. Dinauer, and A. J. Thrasher, "Gene therapy of chronic granulomatous disease: the engraftment dilemma," Molecular Therapy, vol. 19, no. 1, pp. 28-35, 2011.

[312] W. Qasim and A. R. Gennery, "Gene therapy for primary immunodeficiencies: current status and future prospects," Drugs, vol. 74, no. 9, pp. 963-969, 2014.

[313] E. M. Kang, U. Choi, N. Theobald et al., "Retrovirus gene therapy for X-linked chronic granulomatous disease can achieve stable long-term correction of oxidase activity in peripheral blood neutrophils," Blood, vol. 115, no. 4, pp. 783-791, 2010.

[314] M. G. Ott, M. Schmidt, K. Schwarzwaelder et al., "Correction of X-linked chronic granulomatous disease by gene therapy, 
augmented by insertional activation of MDS1-EVI1, PRDM16 or SETBP1," Nature Medicine, vol. 12, no. 4, pp. 401-409, 2006.

[315] G. Farinelli, V. Capo, S. Scaramuzza, and A. Aiuti, "Lentiviral vectors for the treatment of primary immunodeficiencies," Journal of Inherited Metabolic Disease, vol. 37, no. 4, pp. 525-533, 2014.

[316] G. Santilli, E. Almarza, C. Brendel et al., "Biochemical correction of X-CGD by a novel chimeric promoter regulating high levels of transgene expression in myeloid cells," Molecular Therapy, vol. 19, no. 1, pp. 122-132, 2011. 


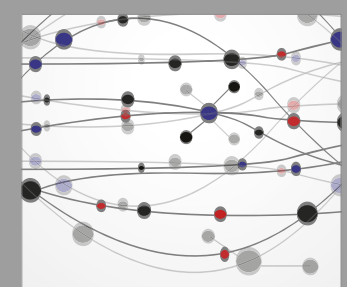

The Scientific World Journal
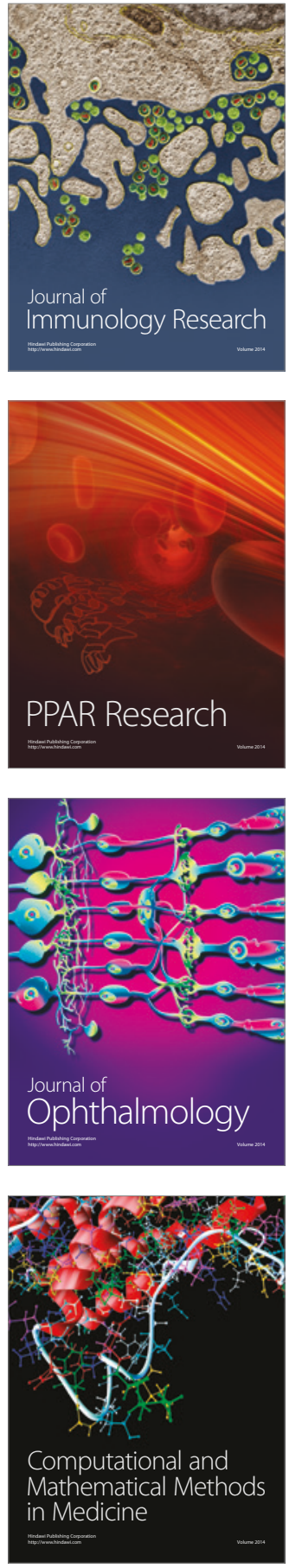

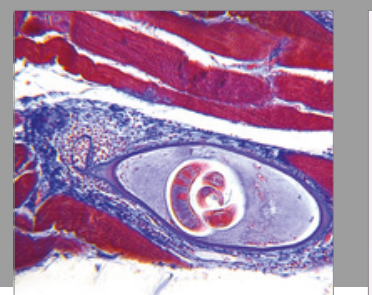

Gastroenterology Research and Practice
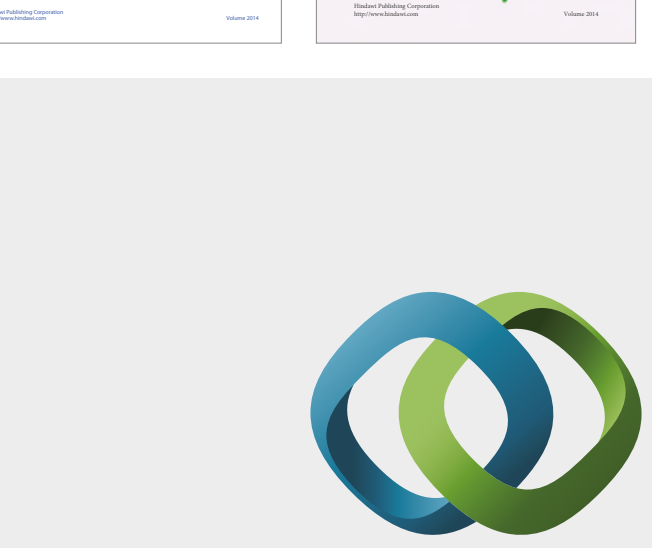

\section{Hindawi}

Submit your manuscripts at

https://www.hindawi.com
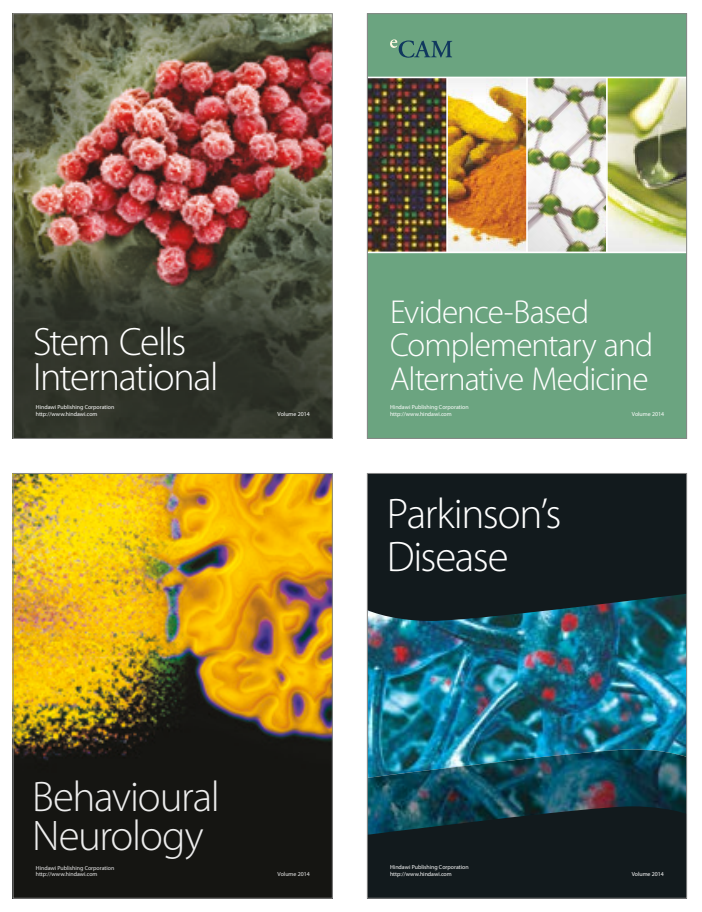
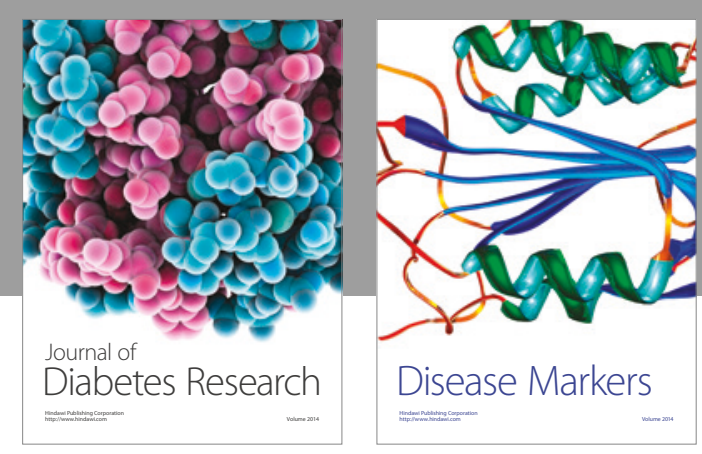

Disease Markers
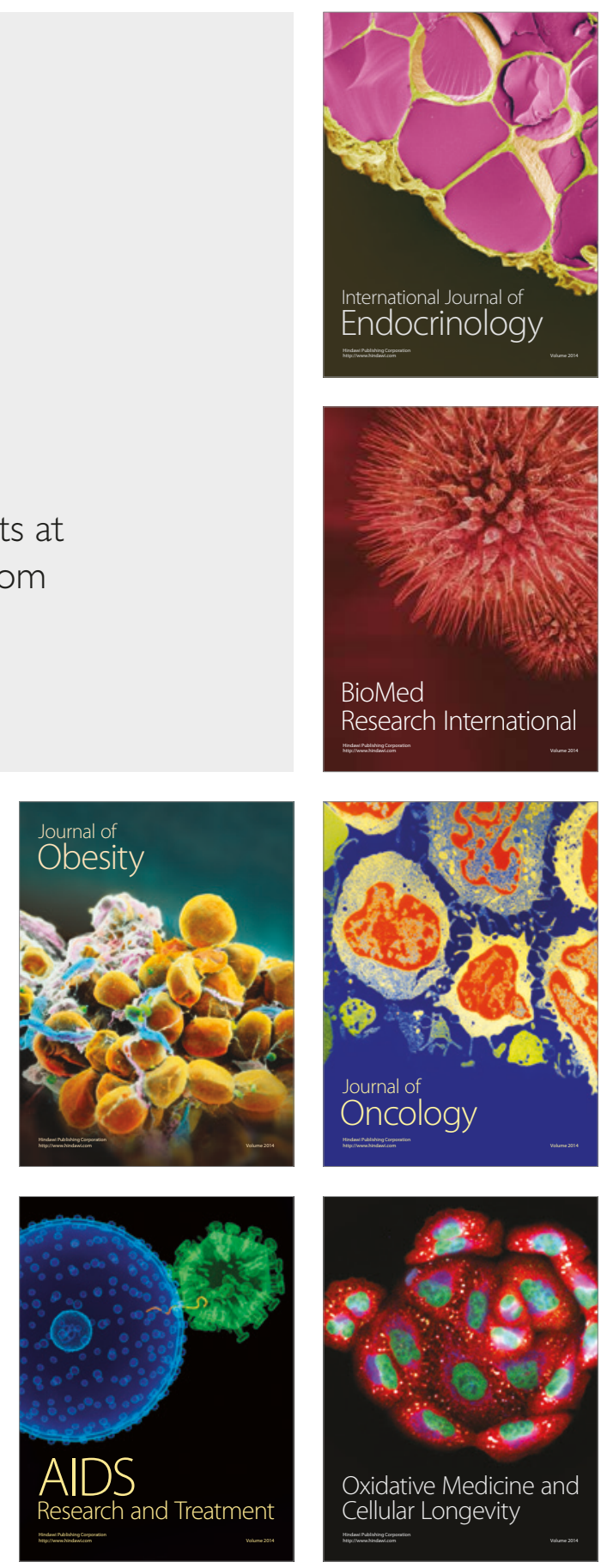